\title{
Tratamiento quirúrgico de la obesidad: recomendaciones prácticas basadas en la evidencia
}

\author{
Bariatric surgery: evidence-based practical recommendations
}

\author{
M. José Morales ${ }^{\mathrm{a}}$, M. Jesús Díaz-Fernández ${ }^{\mathrm{b}}$, Assumpta Caixàs ${ }^{\mathrm{c}}$, Albert Goday ${ }^{\mathrm{d}}$, José \\ Moreiro $^{\mathrm{e}}$, Juan José Arrizabalaga ${ }^{\mathrm{f}}$, Alfonso Calañas-Continente ${ }^{\mathrm{g}}$, Guillem Cuatrecasas ${ }^{\mathrm{h}}$, \\ Pedro Pablo García-Luna, Lluís Masmiquel ${ }^{\mathrm{j}}$, Susana Monereo ${ }^{\mathrm{k}}$, Basilio Moreno, \\ Wilfredo Ricart ${ }^{\mathrm{m}}$, Josep Vidal ${ }^{\mathrm{n}}$, Fernando Cordido ${ }^{\mathrm{o}}$
}

\footnotetext{
${ }^{a}$ Sección de Endocrinología y Nutrición. Hospital do Meixoeiro. Complexo Hospitalario Universitario de Vigo. Pontevedra. España

${ }^{b}$ Sección de Endocrinología y Nutrición. Hospital Valle del Nalón. Asturias. España

${ }^{c}$ Unidad de Diabetes, Endocrinología y Nutrición. Hospital de Sabadell. Sabadell. Barcelona. España

${ }^{d}$ Servicio de Endocrinología. Hospital del Mar. Barcelona. España

e Servicio de Endocrinología y Nutrición. Hospital Comarcal de Inca. Mallorca. Islas Baleares. España

${ }^{f}$ Unidad de Nutrición y Dietética. Hospital Txagorritxu. Vitoria-Gasteiz. Álava. España

${ }^{g}$ Servicio de Endocrinología y Nutrición. Hospital Universitario Reina Sofía. Córdoba. España

${ }^{h}$ Servicio de Endocrinología. Centro Médico Teknon. Barcelona. España

${ }^{i}$ Unidad de Nutrición. Unidad de Gestión de Endocrinología y Nutrición. Hospital Universitario Vírgen del Rocío. Sevilla. España

${ }^{j}$ Sección de Endocrinología. Hospital Son Llàtzer. Palma de Mallorca. Islas Baleares. España

${ }^{k}$ Sección de Endocrinología y Nutrición. Hospital Universitario de Getafe. Madrid. España

${ }^{l}$ Unidad de Obesidad. Servicio de Endocrinología y Nutrición. Hospital Universitario Gregorio Marañón. Madrid. España

${ }^{m}$ Servicio de Diabetes, Endocrinología y Nutrición. Hospital Universitario Josep Trueta. Girona. España

${ }^{n}$ Unidad Funcional de Obesidad. Servicio de Endocrinología y Diabetes. Hospital Clínic. Barcelona. España

${ }^{o}$ Servicio de Endocrinología. Complexo Hospitalario Universitario Juan Canalejo. Departamento de Medicina.

Universidad de A Coruña. A Coruña. España
} 
La obesidad mórbida es, habitualmente, refractaria a los tratamientos convencionales, por lo que la modificación de hábitos dietéticos y de actividad física y/o el uso de fármacos consiguen pérdidas de peso parciales con habitual recuperación posterior. La cirugía bariátrica constituye una opción terapéutica para los casos de obesidad con elevado índice de masa corporal (IMC) asociada a comorbilidades, con buenos resultados a corto y largo plazo.

El Grupo de Trabajo sobre Obesidad de la Sociedad Española de Endocrinología y Nutrición (GOSEEN) ha elaborado un documento con recomendaciones prácticas basadas en la evidencia para el tratamiento quirúrgico de la obesidad.

La revisión se estructura en 3 partes. En la primera se definen los conceptos de obesidad y comorbilidades asociadas, los tratamientos médicos y sus resultados, las indicaciones y contraindicaciones para el tratamiento quirúrgico con los criterios de selección de los pacientes, el manejo pre y perioperatorio y la valoración de grupos especiales, como adolescentes y personas de edad avanzada. En la segunda parte se describen las distintas técnicas quirúrgicas, las vías de acceso y los resultados comparativos, las complicaciones tanto a corto como a largo plazo, la repercusión de la pérdida ponderal sobre las comorbilidades y los criterios para evaluar la efectividad de la cirugía. En la tercera parte se desarrolla el seguimiento postoperatorio, el control dietético en fases tempranas y más tardías tras la cirugía, y el calendario de control médico y analítico con la suplementación de los distintos macro y micronutrientes en función de la técnica quirúrgica empleada. Se incluye un apartado final sobre gestación y cirugía bariátrica, así como tablas y gráficos complementarios al texto desarrollado.

La cirugía bariátrica sigue siendo un tratamiento discutido para la obesidad, pero los resultados en la corrección del exceso ponderal con mejoría en las patologías asociadas y en la calidad de vida confirman que puede ser el tratamiento de elección en pacientes seleccionados, con la técnica quirúrgica apropiada y con un correcto control pre y postoperatorio.

Morbid obesity is usually refractory to conventional treatments. Consequently, weight that is lost by modifying diet and exercise and/or the use of drugs is usually later regained. Bariatric surgery constitutes a therapeutic option in obese patients with a high body mass index associated with comorbidities and achieves good results in both the short and the long term.

The Obesity Working Group of the Spanish Society of Endocrinology and Nutrition has produced a document with practical, evidencebased recommendations for the surgical treatment of obesity.

The review is structured in three parts. The first part defines the concepts of obesity and associated comorbidities, medical treatments, their results, and the indications and contraindications for surgical treatment, as well as the criteria for patient selection, pre- and perisurgical management, and assessment of special groups such as adolescents and the elderly. The second part discusses the different surgical techniques, approaches and comparative results, short- and long-term complications, the repercussions of weight loss on comorbidities, and the criteria for assessing the effectiveness of surgery. The third part discusses postsurgical follow-up, dietary control in the early and subsequent stages after surgery and the schedule for medical and laboratory follow-up, together with the different macro- and micronutrient supplements that should be used depending on the surgical technique employed. A final section is included on pregnancy and bariatric surgery, as well as tables and figures that complement the text.

Although bariatric surgery continues to be a questionable treatment for obesity, the results correcting excess weight, with improvements in associated comorbidities and in quality of life, confirm that this option could be the treatment of choice in selected patients when the appropriate surgical technique and correct preand postoperative follow-up are employed.

\section{Palabras clave}

Obesidad mórbida; Cirugía bariátrica; Recomendaciones prácticas; Valoración preoperatoria; Técnicas quirúrgicas; Seguimiento postoperatorio; Gestación y cirugía bariátrica

Key words

Morbid obesity; Bariatric surgery; Practical recommendations; Presurgical assessment; Surgical techniques; Postsurgical follow-up; Pregnancy and bariatric surgery 


\section{INTRODUCCIÓN}

Durante los últimos años, se ha producido un crecimiento exponencial de la cirugía bariátrica (CB) para el tratamiento de la obesidad grave o mórbida $(\mathrm{OM})$ en todo el mundo, al que han contribuido, entre otros factores, la demostración de sus buenos resultados para conseguir una pérdida de peso efectiva y mantenida en el tiempo, el incremento de la prevalencia de obesidad (y de los casos de OM), el fracaso del tratamiento conservador a largo plazo en este tipo de pacientes y la implantación progresiva del tratamiento laparoscópico.

A pesar de sus beneficios, la CB presenta riesgo de mortalidad y de complicaciones potencialmente graves a corto y largo plazo. La complejidad, tanto de los pacientes como de la propia intervención, hace imprescindible una valoración preoperatoria cuidadosa y un seguimiento postoperatorio atento por parte de un equipo hospitalario multidisciplinario, que trabaje de forma coordinada y con protocolos estandarizados. Dentro de este equipo, las funciones del endocrinólogo deben centrarse en la selección adecuada de los pacientes con criterios médicos de inclusión en un programa de $\mathrm{CB}$, en la valoración y la preparación preoperatoria de los pacientes seleccionados y en el seguimiento médico y nutricional postoperatorio a corto y largo plazo.

El aumento progresivo del número de pacientes con $\mathrm{OM}$ incluidos en programas de $\mathrm{CB}$, y sus necesidades especia- les, exigen que un número cada vez mayor de especialistas deba familiarizarse con el tratamiento de estos pacientes, y disponer de información actualizada y de buena calidad. Sin embargo, la evidencia científica sobre la eficacia y la seguridad de la CB es todavía limitada, debido a la existencia de pocos ensayos controlados y aleatorizados (ECA) con un buen tamaño muestral y con períodos de seguimiento prolongados, a la heterogeneidad de los parámetros utilizados para la medida de los resultados y a los diferentes procedimientos quirúrgicos utilizados.

Para facilitar a los endocrinólogos, y a otros profesionales implicados en la atención a los pacientes con OM, la toma de decisiones relacionadas con los aspectos médicos y nutricionales de la $\mathrm{CB}$, el grupo de trabajo sobre obesidad de la Sociedad Española de Endocrinología y Nutrición se propuso elaborar una guía de recomendaciones prácticas basadas en la evidencia científica disponible y en el consenso de los miembros del grupo.

Tras una búsqueda bibliográfica amplia en bases de datos médicas (Medline, Cochrane Library, EMBASE), se seleccionaron los trabajos más relevantes publicados en los últimos años (hasta diciembre de 2006), incluidos revisiones sistemáticas, metaanálisis, ECA, informes de agencias de evaluación de tecnologías sanitarias y guías de práctica clínica basadas en la evidencia. Además, se consultaron documentos de consenso, revisiones no sistemáticas y artículos originales relacionados con el tratamiento médico y quirúrgico de la obesidad. Con la información obtenida, hemos redactado el documento y formulado grados de recomendación (A, B, C y D), asociados a los diferentes niveles de evidencia, según los criterios de la Scottish Intercollegiate Guidelines Network (SIGN), expuestos en la tabla 1 (pueden consultarse online en la página web www.sign.ac.uk). 
TABLA 1. Grados de recomendación (www.sign.ac.uk)

Grado de recomendación A

Al menos un metaanálisis, una revisión sistemática de EAC o un EAC de alta calidad y

con riesgo de sesgo muy bajo Metaanálisis, revisiones sistemáticas y/o EAC bien

desarrollados y con riesgo de sesgo bajo, que muestran coherencia en sus resultados

Grado de recomendación $B$

Revisiones sistemáticas de estudios de casos y controles o de estudios de cohortes de alta calidad

Estudios de casos y controles, y estudios de cohortes con riesgo de sesgo muy bajo y con probabilidad elevada de que la relación sea causal

Evidencia extrapolada a partir de metaanálisis, revisiones sistemáticas de EAC o EAC

de buena calidad y con riesgo de sesgo bajo

Grado de recomendación $C$

Estudios de casos y controles y estudios de cohortes bien desarrollados y con

probabilidad moderada de que la relación sea causal, que muestran coherencia en sus

resultados

Evidencia extrapolada a partir de revisiones sistemáticas de estudios de casos y controles o de estudios de cohortes de alta calidad o de estudios de casos y controles, y de estudios de cohortes con riesgo de sesgo muy bajo

Grado de recomendación $D$

Estudios no analíticos, como informes de casos y series de casos

Opinión de expertos

Evidencia extrapolada desde estudios de casos y controles, y estudios de cohortes con

riesgo de sesgo bajo

EAC: estudio aleatorizado y controlado.

Todos los estudios deben ser directamente aplicables a la población diana.

\section{INDICACIONES, VALORACIÓN Y CONTROL PREOPERATORIO}

\section{Obesidad. Concepto}

La obesidad es una enfermedad crónica que se caracteriza por un exceso de grasa corporal, que condiciona un aumento de la morbimortalidad en la persona que la presenta. El diagnóstico se realiza mediante el índice de masa corporal (IMC). Se calcula con la siguiente fórmula: peso en kilogramos dividido por altura en metros al cuadrado. Es válido para personas adultas, de edad igual o superior a 18 años, en ambos sexos.

Se considera que hay obesidad ${ }^{1}$ cuando el IMC es igual o superior a 30 , y obesidad clínicamente grave (grado III) si es igual o superior a 40 (tabla 2). De acuerdo con los criterios adoptados por la Sociedad Americana de Cirugía Bariátrica ${ }^{2}$, puede subclasificarse en obesidad mórbida (OM, IMC = 35-39,9 con comorbilidades mayores o IMC $=40-49,9)$, superobesidad mórbida ( $\mathrm{SOM}, \mathrm{IMC}=50-59,9$ ), su- persuperobesidad $($ SSOM, IMC $=60-64,9)$ y obesidad triple $(\mathrm{IMC}>65)$, cara a delimitar el riesgo global del paciente, el riesgo quirúrgico y la selección de la técnica quirúrgica.

Tanto el exceso de grasa corporal, como su localización, son importantes. La distribución central de la grasa es un factor de riesgo independiente por su asociación con aumento del riesgo cardiovascular. Para su valoración, se recomienda medir el perímetro de la cintura sobre el borde superior de las crestas ilíacas (en el punto medio entre la última costilla y la cresta ilíaca, en espiración no forzada). Según el consenso de la Sociedad Española para el Estudio de la Obesidad (SEEDO) del año $2000^{3}$, se considera patológica si es superior a $102 \mathrm{~cm}$ en el varón y $90 \mathrm{~cm}$ en la mujer, aunque en la última revisión de la $\mathrm{SEEDO}^{4}$ ya no se mencionen estas cifras. Las más utilizadas son las de los National Institutes of Health $(\mathrm{NIH})^{5}$ de Estados Unidos, $102 \mathrm{~cm}$ para el varón y $88 \mathrm{~cm}$ para la mujer. Recientemente, la International Diabetes 
Federation ha propuesto puntos de corte distintos en función del grupo étnico, siendo para la raza caucásica $94 \mathrm{~cm}$ en los varones y $80 \mathrm{~cm}$ en las mujeres ${ }^{6}$.

TABLA 2. Clasificación del peso corporal en función del índice de masa corporal (IMC) ${ }^{1}$

\begin{tabular}{ll}
\hline Categoría & $\mathrm{IMC}\left(\mathrm{kg} / \mathrm{m}^{2}\right)$ \\
\hline & \\
Normopeso & $18,5-24,9$ \\
Sobrepeso & $25-29,9$ \\
Obesidad grado I & $30-34,9$ \\
Obesidad grado II & $35-39,9$ \\
Obesidad grado III & $>40$ \\
\hline
\end{tabular}

IMC: índice de masa corporal.

\section{Prevalencia}

El exceso de peso es, en este momento, un grave problema en todos los países industrializados y, de forma creciente, en los que están en vías de desarrollo, estimándose en 1.700 millones de personas las que cumplen criterios de sobrepeso/obesidad en todo el mundo (igualando en número a las personas con desnutrición/bajo peso) ${ }^{7}$.

En Estados Unidos, 2 terceras partes de la población tiene exceso de peso (aproximadamente 1 de cada 4 adultos es obeso, es decir, unos 50 millones de personas ${ }^{8}$. Recientemente, se han publicado en España los resultados de la recopilación de los estudios de ámbito nacional (siguiendo protocolos estandarizados) con los datos de peso y talla de la población española, para conocer la prevalencia del sobrepeso y la obesidad ${ }^{9}$. Según el estudio SEEDO' $2000^{10}$, en España, un $14,5 \%$ de la población adulta (entre 25 y 60 años) cumplía criterios de obesidad, y, lo que es más importante, según el estudio enKid ${ }^{11}$, realizado en población infantil y juvenil española de 2-24 años, un 12,4\% tiene sobrepeso y un 13,9\%, obesidad. En el estudio DORICA ${ }^{12}$, realizado en población adulta española de 25-64 años, se estimó una prevalencia de obesidad del $13,2 \%$ en varones y del $17,5 \%$ en mujeres, lo que añadido al $46,4 \%$ de varones y del 32,9\% de mujeres con sobrepeso, da una cifra de exceso de peso de la población adulta española del $54,7 \%$.

La prevalencia de obesidad mórbida es más difícil de establecer, dada la escasez de estudios sobre el problema. En adultos de Estados Unidos era del 4,8\% (el 2,8\% en varones y el 6,9\% en mujeres) en 2004, según Ogden et $a^{13}{ }^{13}$. En España, según el mismo estudio, DORICA ${ }^{12}$, la presentan un 0,3\% de los varones y un $0,9 \%$ de las mujeres (lo que supone un $4 \%$ de las personas obesas), aumenta con la edad y en todos los grupos de edad es 3 o 4 veces superior en las mujeres.

\section{Comorbilidades}

Se consideran comorbilidades de la obesidad los estados patológicos susceptibles de curación o mejoría con la pérdida de peso ${ }^{14}$. La obesidad se asocia con un incremento de la mortalidad, después del ajuste de las distintas variables ${ }^{15}$, y es un factor de riesgo independiente para el infarto agudo de miocardio no fatal y para la cardiopatía isquémica ${ }^{16}$. La asociación de la obesidad con el aumento de la presión arterial (PA) sistólica y diastólica, y con el aumento de los valores de colesterol, triglicéridos y colesterol unido a lipoproteínas de baja densidad está bien documentada ${ }^{17}$, así como el riesgo de desarrollar diabetes mellitus (DM), aun de forma in- dependiente a otros factores de riesgo, como antecedentes familiares y edad ${ }^{18,19}$. 
Asimismo, se ha observado una asociación entre obesidad y aparición de cáncer en distintas localizaciones (mama, colon, próstata, riñón, endometrio y vesícula biliar) ${ }^{20}$. La obesidad también se asocia a esteatosis hepática, a afectación de articulaciones por sobrecarga (rodillas, caderas) y por probables efectos metabólicos (osteoartritis en manos), a trastornos respiratorios durante el sueño ${ }^{21}$ y a complicaciones durante el embarazo (malformaciones fetales por alteración del tubo neural, mayor riesgo de cesárea $)^{22}$. En la tabla 3 se enumeran las comorbilidades mayores y menores de la obesidad, según el riesgo vital o la repercusión en la calidad de vida.

TABLA 3. Comorbilidades mayores y menores de la obesidad

\begin{tabular}{ll}
\hline Mayores & Menores \\
\hline Diabetes mellitus tipo 2 & Esteatosis hepática \\
HTA & Colelitiasis \\
Dislipemia & Reflujo gastroesofágico \\
Enfermedad cardiovascular & Alteraciones menstruales \\
SAOS/SHO & Infertilidad \\
Osteoartropatía grave & Incontinencia urinaria de esfuerzo \\
& Varices \\
& Hipertension intracraneal benigna \\
\hline
\end{tabular}

HTA: hipertensión arterial; SAOS: síndrome de apnea obstructiva del sueño; SHO: síndrome de hipoventilación-obesidad.

En las formas graves de obesidad hay una alta prevalencia de trastornos psiquiátricos. En algunos casos, se trata de un trastorno psiquiátrico primario que actúa como precipitante o mantenedor del exceso de peso patológico, como ocurre en el trastorno por "atracones". Sin embargo, la mayoría de las veces son secundarios a los problemas psicosociales derivados de la obesidad.

Los diagnósticos psiquiátricos más prevalentes en pacientes con $\mathrm{OM}$ candidatos a $\mathrm{CB}$ incluyen ${ }^{23,24}$ :

- Trastorno por atracones (hasta un tercio de los pacientes con OM).

- Bulimia atípica.

- Trastornos afectivos.

- Trastornos adaptativos.

- Trastornos de personalidad.

La presencia de un trastorno psiquiátrico condiciona las perspectivas de éxito del tratamiento quirúrgico, por lo que es necesaria una valoración psicológica y psiquiátrica preoperatoria que permita diagnosticar los trastornos psiquiátricos que contraindiquen la $\mathrm{CB}$, de manera absoluta o relativa.

\section{Resultados del tratamiento médico}

La OM es, habitualmente, refractaria a tratamientos médicos convencionales (modificación de hábitos -ingesta y actividad física- y/o tratamiento farmacológico), con ocasionales pérdidas moderadas de peso, que hasta en un $95 \%$ de los pacientes se recupera o incluso se supera a los 2 años ${ }^{25}$. (Grado de recomendación $A$ )

Esto condiciona que, en estadísticas de salud realizadas, un $40 \%$ de las mujeres y un $25 \%$ de los varones confiesen utilizar distintos métodos de forma habitual (frecuente- mente sin control médico) para disminuir su peso corporal. En Estados Unidos se ha estimado que a 4,5 millones de personas se les prescribió medicación para disminuir de peso entre 1996-1998 ${ }^{26}$. Actualmente, disponemos de fármacos que actúan en la regulación del apetito o en la absorción intestinal de las grasas ingeridas. En un 
metaanálisis reciente ${ }^{27}$ de los últimos ensayos clínicos realizados sobre eficacia y seguridad con los fármacos aprobados por la Food and Drug Administration (FDA), y otros utilizados en el tratamiento de la obesidad, se concluye que la sibutramina, el orlistat, la fentermina, el bupropión, el topiramato y, con resultados más dudosos, la fluoxetina y el dietilpropión promueven una pérdida de peso modesta, pero clínicamente y estadísticamente significativa. Los más estudiados, el orlistat y la sibutramina, son también los más utilizados en España. Está pendiente de autorización para su comercialización el rimonabant, un bloqueador selectivo de los receptores cannabinoides CB1, con efecto potencial en el control del peso corporal y el síndrome metabólico. Con este fármaco, la pérdida ponderal a largo plazo también es modesta ${ }^{28,29}$.

Por tanto, el tratamiento médico, ya sea con dieta sola o asociada a fármacos, es poco efectivo a largo plazo en términos de pérdida ponderal.

\section{Justificación del tratamiento quirúrgico}

Hay estudios comparativos entre tratamiento médico y quirúrgico de la obesidad mórbida. En el de Andersen et $\mathrm{al}^{30}$, en que se compara gastroplastia horizontal con dietas muy bajas en calorías, sólo se observaron diferencias entre los 2 tratamientos a partir de los 24 meses, y la tasa de éxito acumulada a los 5-6 años fue del 16\% para los pacientes operados y del 2\% para los que sólo recibieron dieta. En el estudio $\mathrm{SOS}^{31,32}$, en el que se comparan 3 tipos de intervención quirúrgica frente a tratamiento dietético convencional, se observó una pérdida de peso significativamente mayor, a los 2 y a los 8 y 10 años, en los pacientes sometidos a intervención quirúrgica. Además, la pérdida de peso posquirúrgica se asoció a mejorías significativas de la calidad de vida y de algunas comorbilidades.

Revisiones sistemáticas y metaanálisis recientes ${ }^{33-35}$ corroboran los resultados anteriores. En resumen, hay suficientes datos que demuestran que la intervención quirúrgica es más efectiva que el tratamiento convencional para conseguir pérdidas de peso a largo plazo y mejorar la calidad de vida y algunas comorbilidades. (Grado de recomendación A)

\section{Indicaciones de la cirugía bariátrica}

A pesar de su superioridad frente al tratamiento médico, la CB es una cirugía abdominal de alto riesgo, tanto por la complejidad de los pacientes como de las propias técnicas quirúrgicas, por lo que debe formar parte de una estrategia global y coherente en el tratamiento del paciente obeso ${ }^{36}$.

La indicación del tratamiento quirúrgico de la obesidad, por tanto, requerirá:

1. Comprobación del fracaso del tratamiento médico previo de la obesidad.

2. Adecuada y completa información sobre las posibilidades de la CB.

3. Valoración multidisciplinaria (nutricional, quirúrgica, anestésica y psicológica) del paciente.

4. Control médico y quirúrgico, preoperatorio y postoperatorio.

(Grado de recomendación D)

Las indicaciones actuales de la CB, basadas en los criterios establecidos en 1991 por un comité de expertos de los NIH de Estados Unidos ${ }^{37}$, se recogen en la declaración de Salamanca de la Sociedad Española de Cirugía de la Obesidad (SECO) 38 (tabla 4).

La selección de los pacientes por un equipo hospitalario multidisciplinario integrado por cirujanos, endocrinólogos, psiquiatras, psicólogos y dietistas, o personal de enfermería especializado en nutrición, puede reducir los riesgos del tratamiento quirúrgico. La identificación de las contraindicaciones, el control preoperatorio de los factores de riesgo y un cuidadoso abordaje preoperatorio, intraoperatorio y postoperatorio, mejoran los resultados de la intervención ${ }^{36-38}$. (Grado de recomendación D) 
Obesidad con IMC $\geq 40$ o $>35-39,9 \mathrm{~kg} / \mathrm{m}^{2}$ con comorbilidades mayores

Edad entre 18 y 55 años (flexible, según el caso clínico)

Duración de la obesidad mórbida superior a 5 años

Fracasos previos del tratamiento médico

Ausencia de enfermedad psiquiátrica y/o trastornos de la conducta alimentaria activos y de abuso

de drogas y/o alcohol

Capacidad para comprender, comprometerse y adherirse a los cambios que supone la cirugía

bariátrica

Ausencia de enfermedad endocrinológica que justifique la obesidad y de otra enfermedad que

contraindique la cirugía

IMC: índice de masa corporal.

\section{Poblaciones especiales}

\section{Adolescencia}

La evidencia disponible del tratamiento quirúrgico en población adolescente es muy limitada y los datos existentes en los adultos no pueden extrapolarse a los adolescentes. Sin embargo, el aumento de la prevalencia de $\mathrm{OM}$ en la edad pediátrica y la adolescencia, con comorbilidades graves cada vez más frecuentes $^{39}$, hacen que el límite de edad mínimo para la CB sea un tema controvertido.

Una revisión sistemática de los resultados publicados sobre CB en la adolescencia permite deducir que es segura y produce una pérdida significativa de peso, con corrección de las comorbilidades y mejora de la imagen corporal y de la socialización ${ }^{40}$, y es fundamental un estricta selección de los pacientes de forma individualizada (tabla 5). (Grados de recomendación $C$ y D)

La indicación de CB podría considerarse en centros con una amplia experiencia en el tratamiento quirúrgico en adultos y con capacidad para ofrecer un tratamiento multidisciplinario, incluidos aspectos pediátricos relativos a la cirugía y al tratamiento dietético y psicológico ${ }^{41}$. 
TABLA 5. Criterios de cirugía bariátrica en adolescentes. Valoración cuidadosa individualizada (caso por caso), en la que se contrapesan los beneficios de realizar la cirugía en la etapa adolescente en lugar de esperar hasta la vida adulta

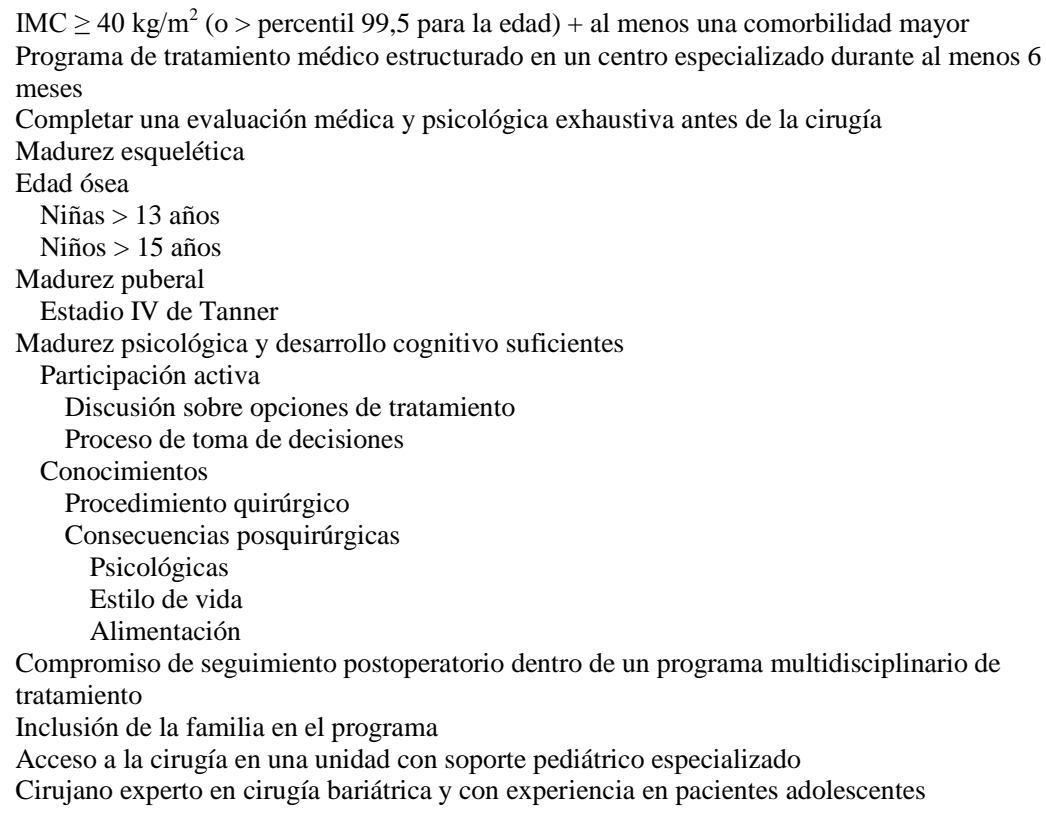

IMC: índice de masa corporal.

\section{Edad avanzada}

En esta población, el objetivo primario del tratamiento quirúrgico es mejorar la calidad de vida (no la longevidad). La indicación de CB en pacientes mayores de 60 años requiere un estudio individualizado, debido al in- cremento del riesgo de complicaciones con la edad avanzada. En el estudio de Flum et al ${ }^{42}$, la tasa de mortalidad postoperatoria temprana en pacientes beneficiarios de Me- dicare mayores de 65 años fue del 4,8\%, comparada con el 1,7\% en menores de 65 años. La mortalidad fue 2,8 veces mayor a los 30 días, 3 veces mayor a los 90 días y 2,85 veces mayor al año. Estos resultados desfavorables con respecto a los publicados previamente se asociaban, además, al sexo (mayor riesgo en varones) y a un bajo volumen de intervenciones del cirujano. Aunque el estudio no encontró datos que demostraran un beneficio de la $\mathrm{CB}$ en la población mayor de 65 años, proporcionó evidencias para apoyar el bypass gástrico (BG) (laparoscópico y abierto) y la banda gástrica ajustable laparoscópica (BGAL), realiza- dos por cirujanos con un alto volumen de intervenciones, en pacientes bien seleccionados por debajo de 65 años. (Grado de recomendación $C$ )

\section{Contraindicaciones de la cirugía bariátrica}

El riesgo de morbimortalidad en pacientes sometidos a $\mathrm{CB}$ se relaciona principalmente con el tipo de intervención quirúrgica, el grado de obesidad, la edad, el sexo, las complicaciones médicas previas y la experiencia del cirujano ${ }^{43}$. 
Los factores (dependientes del paciente) que aumentan el riesgo de mortalidad postoperatoria incluyen:

- IMC elevado (por encima de 50).

- Edad superior a 50 años.

- Sexo masculino.

- Técnica quirúrgica: cirugía revisional > derivación biliopancreática $(\mathrm{DBP})>\mathrm{BG}>\mathrm{BGAL}$

- Algunas comorbilidades: DM, hipertensión arterial (HTA), síndrome de apnea obstructiva del sueño (SAOS). (Grados de recomendación B y C)

En pacientes correctamente seleccionados para $\mathrm{CB}$, se ha observado que, de las distintas variables estudiadas, la edad es un parámetro relacionado con las complicaciones posquirúrgicas y el IMC con un aumento del tiempo operatorio y con la frecuencia de reconversión de la cirugía ${ }^{44,45}$.

Las contraindicaciones médicas para la cirugía se relacionan con enfermedades graves con afectación vital y/o que no mejoran con la intervención, o con malas expectativas de vida a corto y medio plazo ${ }^{46}$ :

- Cáncer de pronóstico indeterminado.

- Enfermedad inflamatoria intestinal.

- Enfermedad cardíaca grave o inestable.

- Enfermedad pulmonar grave.

- Cirrosis hepática.

- Insuficiencia renal.

- Otras condiciones con elevado riesgo operatorio.

\section{Circuito perioperatorio del paciente candidato a cirugía bariátrica}

\section{Selección de pacientes}

Ante un paciente con $\mathrm{OM}$ y fracaso terapéutico a los tratamientos convencionales, se debe plantear si cumple criterios para indicar el tratamiento quirúrgico de su exceso de peso. Este primer paso y los estudios siguientes seguirán un circuito que dependerá de las características de cada centro.

En la mayoría de los casos, el endocrinólogo actúa como primer eslabón del equipo multidisciplinario, y selecciona a los pacientes que cumplen criterios médicos de inclusión. Además, se ocupará de completar el estudio de comorbilidades, establecer las modificaciones terapéuticas necesarias para disminuir el riesgo de la cirugía y, con apoyo de dietistas o personal de enfermería especializado, realizar una valoración nutricional y proporcionar información sobre hábitos alimentarios saludables y modificaciones de la dieta en el postoperatorio.

Posteriormente, remitirá a los pacientes seleccionados al psiquiatra para descartar enfermedades que contraindiquen la intervención y al cirujano, que proporcionará el consentimiento informado, seleccionará finalmente la técnica quirúrgica y completará el estudio preoperatorio.

La valoración psiquiátrica preoperatoria es muy importante, ya que la presencia de psicopatología grave y trastornos del comportamiento alimentario aumentan el riesgo de complicaciones y pueden condicionar un mal resultado ${ }^{47-49}$. 
Los objetivos de esta valoración serían:

- Diagnóstico de trastornos psiquiátricos que contraindiquen la CB (de manera absoluta o relativa, condicionada a su recuperación).

- Tratamiento de estos trastornos.

- Evaluación de las expectativas del paciente cara a la cirugía.

- Valoración del entorno sociofamiliar.

- Mejorar la motivación del paciente.

En algunos casos complicados, especialmente cuando hay contraindicaciones relativas, puede ser preciso tomar la de- cisión conjuntamente y tras sesión clínica.

La pérdida preoperatoria de peso mediante un tratamiento médico intensificado debe ser un objetivo prioritario para intentar disminuir los riesgos quirúrgicos. Se ha descrito que pérdidas moderadas de peso (de entre un 5 y un 10\%), con dietas de muy bajo contenido calórico administradas durante varias semanas antes de la intervención, reducen significativamente el volumen del hígado y del compartimiento adiposo abdominal, lo que facilita el tratamiento laparoscópico ${ }^{50}$. En pacientes superobesos, el tratamiento pre- operatorio con balón intragástrico puede reducir el riesgo de conversión a cirugía abierta y de complicaciones intraoperatorias ${ }^{51}$.

En la figura 1 se muestra el circuito para el tratamiento del paciente con obesidad mórbida ante la posibilidad de $\mathrm{CB}$.

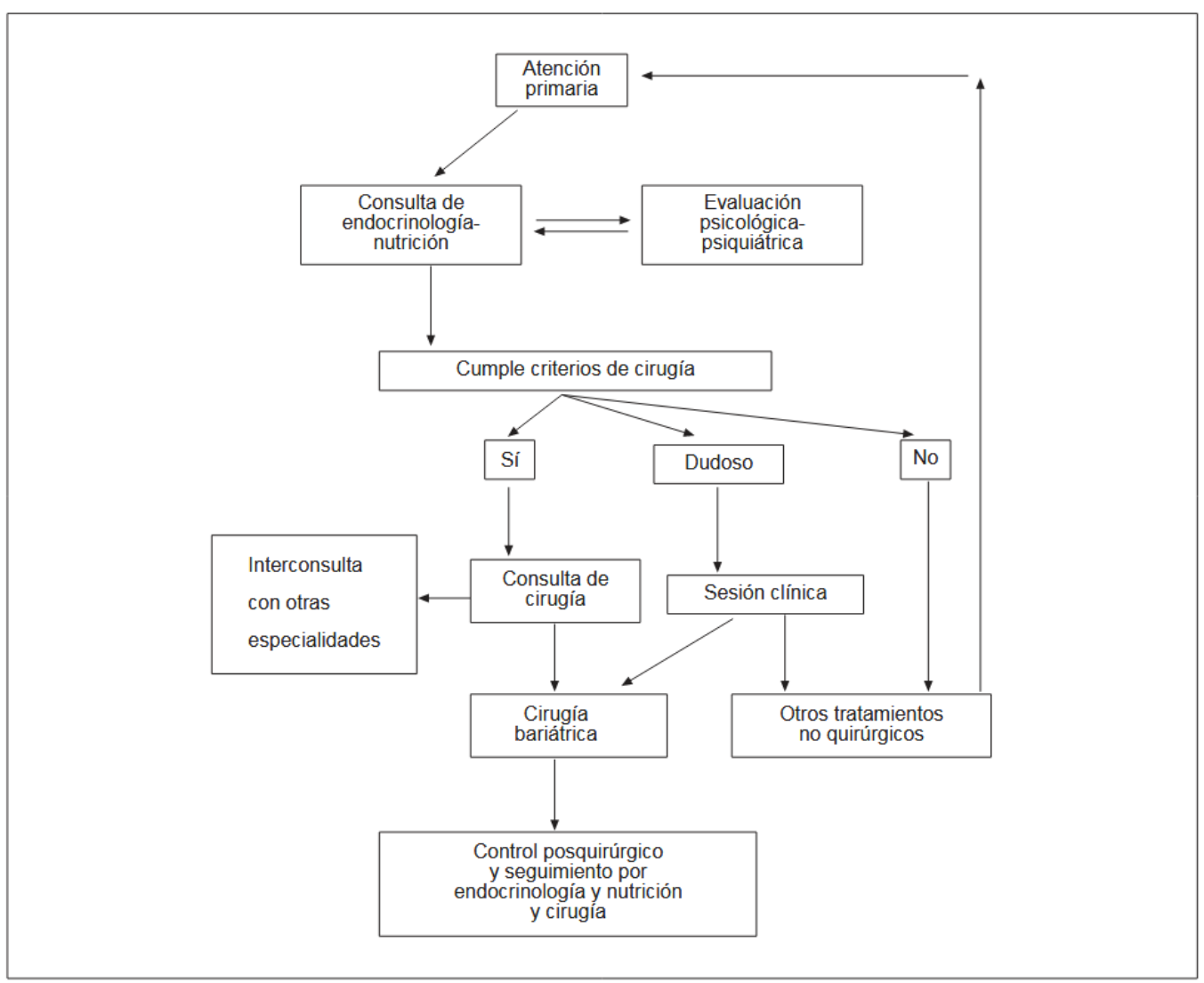

Fig. 1. Circuito perioperatorio del paciente con indicación de cirugía bariátrica. Modificado del protocolo del Hospital Txagorritxu (Vitoria). 


\section{Prioridades}

Dada la creciente demanda del tratamiento quirúrgico de la OM, es importante una selección correcta de los pacientes, y respetar los criterios de inclusión, pero garantizar la accesibilidad de todos ellos a este tratamiento.

La programación de las listas de espera quirúrgica debe aunar el criterio cronológico habitual para el orden de los pacientes con una serie de prioridades que faciliten el tratamiento quirúrgico a los pacientes que más lo necesitan. La introducción de un sistema de puntuación, en el que se consideren diferentes variables, como grado de obesidad, comorbilidad mayor asociada y repercusión social, así como el tiempo de permanencia en lista de espera, permite elegir con objetividad a los pacientes que deben ser operados antes $^{52}$ (tabla 6).

TABLA 6. Sistema de puntuación para la programación y la priorización de las listas de espera quirúrgica

\begin{tabular}{lll}
\hline Criterio & Valoración & Total \\
\hline \multirow{2}{*}{ Grado de obesidad } & $40-49,9$ & 1 \\
& $50-59,9$ & 2 \\
Comorbilidad asociada & HTA & 3 \\
& Cardiopatía & 1 \\
& Dislipemia & 1 \\
& DM tipo 2 & 1 \\
& Osteoartropatía con tratamiento diario & 1 \\
& SAOS con CPAP & 1 \\
& Disnea grado 3-4 & 1 \\
Repercusión & Otra enfermedad quirúrgica abdominal sintomática & 1 \\
sociolaboral & Criterios de calidad de vida (autoestima, higiene personal, & 1 \\
Valoración clínica & aislamiento, dificultades laborales, sexuales) & $1-2$ \\
global & Criterio del equipo médico & $1-3$ \\
Semestres en lista & 1 punto por semestre de espera & \\
&
\end{tabular}

Modificada de Alastrué et $\mathrm{al}^{52}$. CPAP: presión positiva continua en la vía respiratoria; DM: diabetes mellitus; HTA: hipertensión arterial; SAOS: síndrome de apnea obstructiva del sueño.

\section{Tratamiento preoperatorio}

Debería incluir:

- Valoración médica protocolizada.

- Educación nutricional y explicación de los cambios die- téticos en el postoperatorio.

- Optimizar el tratamiento de las comorbilidades para disminuir el riesgo quirúrgico.

- Comprobar que el paciente está bien informado sobre los beneficios, las consecuencias y los riesgos de las opciones quirúrgicas y la necesidad de seguimiento postoperatorio a largo plazo.

- Analizar y mejorar la motivación del paciente y su disposición para adherirse al programa de seguimiento postoperatorio. (Grado de recomendación D)

Además del estudio preoperatorio rutinario como para cualquier otra cirugía abdominal mayor, la valoración médica comprenderá una evaluación clínica, antropométrica y bioquímica (con estudio hormonal), acompañada de otras exploraciones complementarias, para descartar trastornos metabólicos y endocrinos, SAOS y alteraciones de la función pulmonar, trastornos gastroesofágicos, colelitiasis y disfunción cardíaca, principalmente. 
En la tabla 7 se enumeran los estudios recomendados antes de realizar la CB.

TABLA 7. Valoración médica preoperatoria

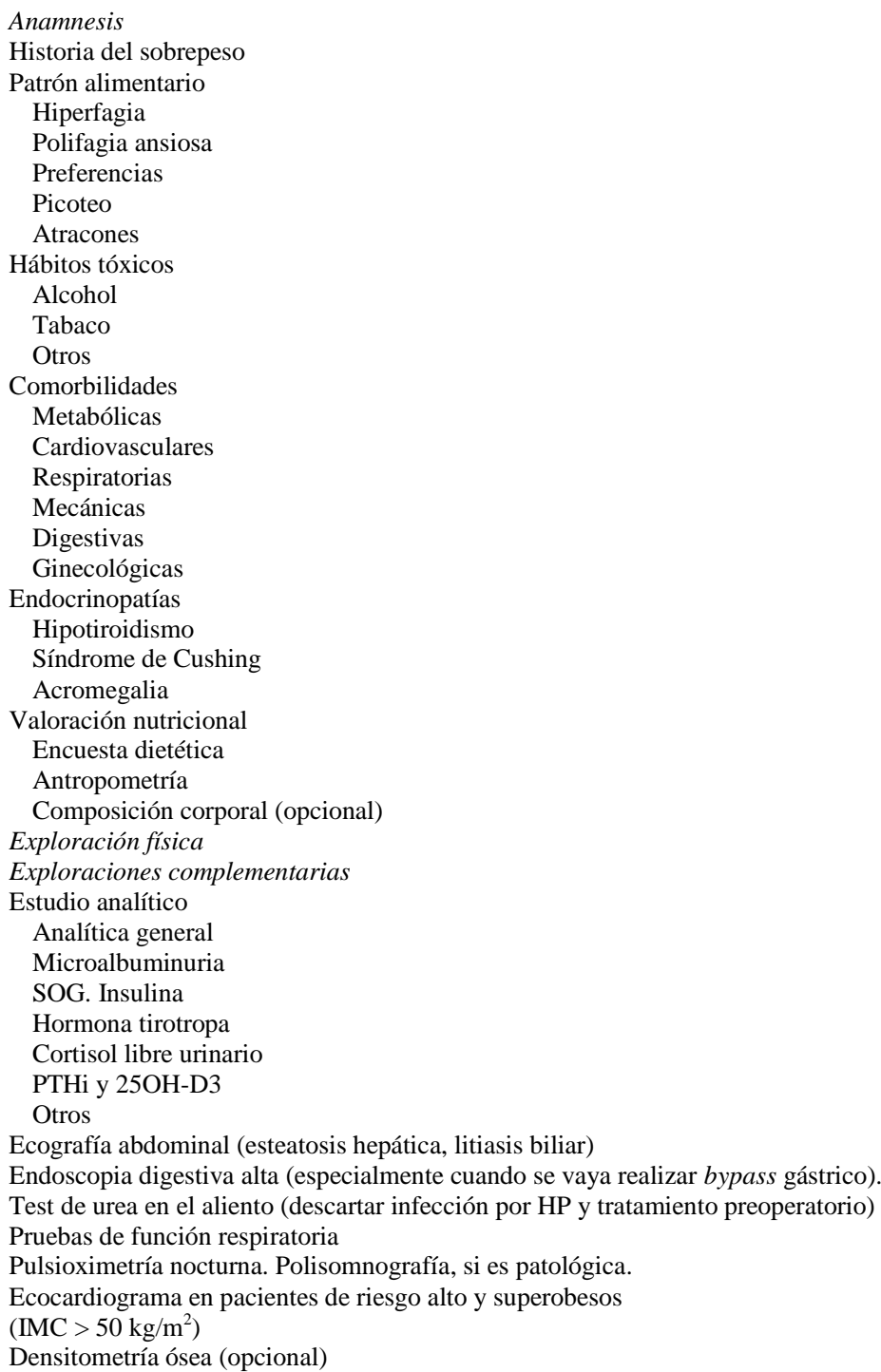

25OH-D ${ }_{3}$ : calcifediol; HP: Helicobacter pylori; IMC: índice de masa corporal; PTHi: hormona paratiroidea intacta; SOG: sobrecarga oral de glucosa. 


\section{Tratamiento perioperatorio}

La revisión de los distintos estudios sobre complicaciones perioperatorias de la $\mathrm{CB}^{43}$ permite hacer algunas recomendaciones específicas para disminuir el riesgo quirúrgico con distintos niveles de evidencia:

1. Trombosis venosa profunda/tromboembolia pulmonar (TVP/TEP)*:

- Profilaxis perioperatoria para tromboembolia en todos los pacientes que van a someterse a CB. (Grados de recomendación A y B)

- Salvo contraindicación, uso de métodos mecánicos combinados con heparina de bajo peso molecular. (Grados de recomendación A y $B$ )

- Colocación preoperatoria de filtro en vena cava inferior en pacientes con riesgo muy elevado. (Grado de recomendación D)

*Factores de riesgo para TEP/TVP: historia previa de episodios tromboembólicos; distribución central de la grasa; tabaquismo; sexo femenino; edad; estasis/insuficiencia venosa; SAOS; hipercoagulabilidad, uso de anticonceptivos orales

2. SAOS:

- Estudio polisomnográfico nocturno para pacientes con episodios de apnea del sueño o clínica diurna indicativa, y en aquellos con HTA, enfermedad cardíaca o edema en las extremidades inferiores. (Grado de recomendación $D$ )

- Seguimiento perioperatorio de los valores de saturación de oxígeno en los pacientes con SAOS. (Grado de recomendación D)

3. Enfermedad hepática:

- Valoración preoperatoria de función hepática en caso de elevación de los valores de transaminasas sin causa justificada. (Grado de recomendación B)

- Biopsia hepática intraoperatoria si se observa enfermedad. (Grado de recomendación B)

- Valorar biopsia hepática si hay DM tipo 2, resistencia a la insulina o hiperferritinemia. (Grado de recomendación $B$ )

4. Tabaquismo:

- Abandono del tabaco, al menos 6-8 semanas antes de la cirugía. (Grado de recomendación D)

- Control dietético/farmacológico para evitar ganancia de peso tras dejar de fumar. (Grado de recomendación $A$ )

- Recomendar mantenerse como no fumador tras la CB. (Grado de recomendación A)

5. Pérdida preoperatoria de peso:

- Aconsejar reducción de peso antes de la cirugía. (Grado de recomendación D)

6. Enfermedad coronaria:

- Tratamiento preoperatorio con bloqueadores beta en pacientes con historia o sospecha de cardiopatía isquémica, si no hay contraindicaciones. (Grado de recomendación A)

7. Profilaxis antibiótica:

- Cefazolina, 2 g por vía intravenosa 30 min antes de la cirugía y otros 2 g después de la cirugía. En pacientes alérgicos, dosis de $1 \mathrm{~g}$ de vancomicina y $80 \mathrm{mg}$ de gentamicina antes y después de la cirugía. (Grado de recomendación D)

8. Control glucémico:

- Perfusión continua de insulina, variando dosificación mediante protocolos estandarizados ${ }^{53}$. (Grado de recomendación $A$ ) 


\section{TÉCNICAS QUIRÚRGICAS}

El objetivo de la $\mathrm{CB}$ es conseguir una pérdida de peso suficiente y mantenida en el tiempo para corregir o controlar las enfermedades asociadas a la OM, y mejorar la calidad de vida del paciente, con un número mínimo de complicaciones.

En general, el tratamiento quirúrgico se basa en 2 principios:

- Limitar la ingesta de alimentos mediante una disminución del volumen gástrico (mecanismo restrictivo).

- Modificar la fisiología de la digestión e inducir una malabsorción parcial, acortando el recorrido de los alimentos a través del intestino (mecanismo derivativo).

A partir de estos mecanismos, hay diferentes opciones quirúrgicas, que pueden clasificarse en las categorías siguientes (fig. 2):

- Procedimientos restrictivos.

- Procedimientos malabsortivos.

- Procedimientos mixtos, restrictivos y malabsortivos.

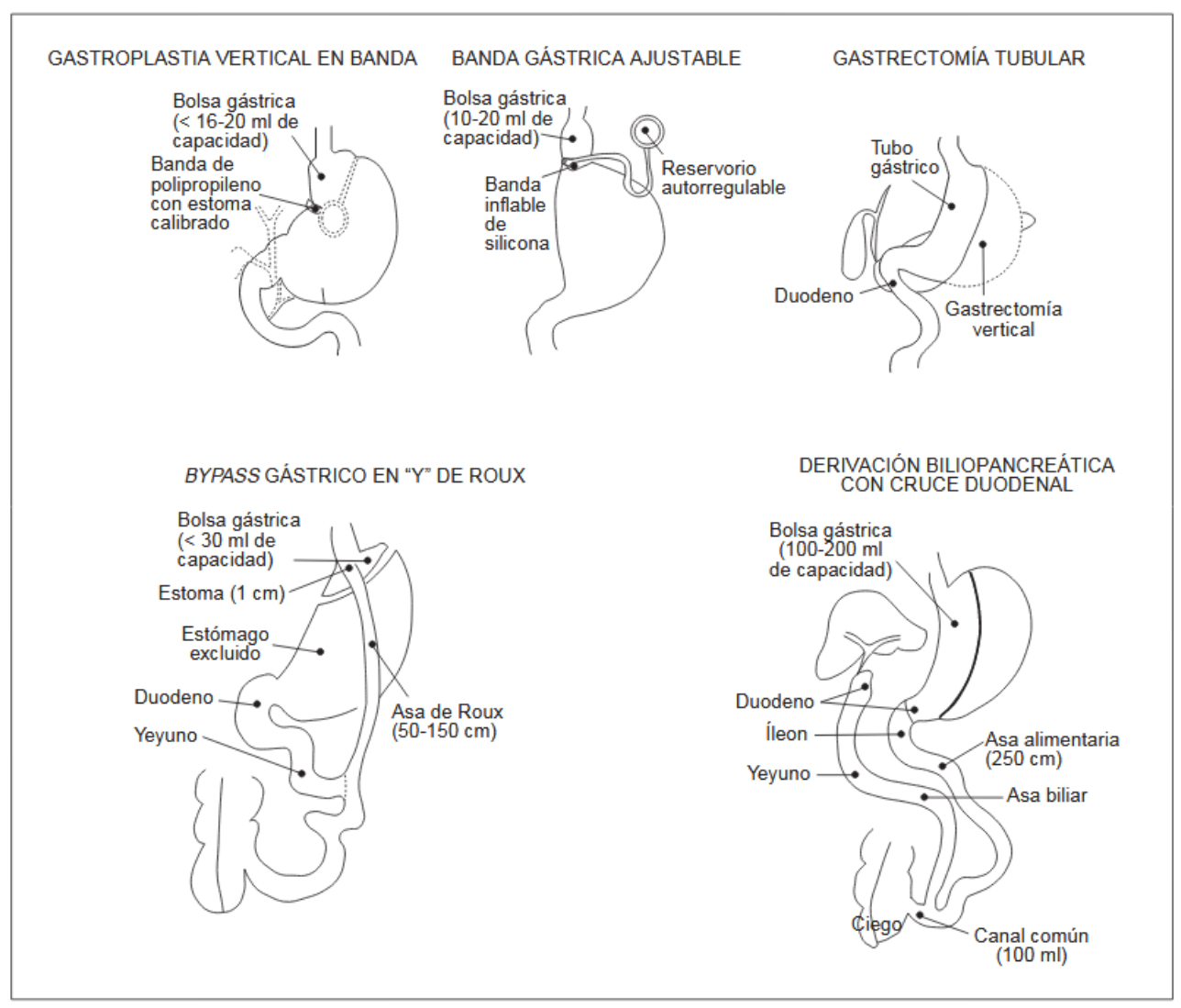

Fig. 2. Técnicas actuales de cirugía bariátrica.

Restrictivas: gastroplastia vertical en banda. Banda gástrica ajustable. Gastrectomía tubular. Mixtas: bypass gástrico en "Y" de Roux. Derivación biliopancreática con cruce duodenal. 
Los diferentes procedimientos pueden realizarse tanto por vía abierta (laparotomía), como por vía laparoscópica.

A medida que aumenta la complejidad de las intervenciones, se incrementa la efectividad de éstas, pero también el riesgo de complicaciones técnicas y nutricionales ${ }^{36-38}$.

\section{Procedimientos restrictivos}

Su objetivo es inducir una sensación de saciedad temprana, con un consumo limitado de alimentos, sin alterar la fisiología digestiva.

Banda gástrica ajustable laparoscópica ${ }^{54,55}$

Es el procedimiento restrictivo más utilizado actualmente, debido a su simplicidad, reversibilidad y menor morbimortalidad perioperatoria, en comparación con otras técnicas bariátricas. Consiste en colocar una banda de silicona inflable alrededor del estómago, cerca de su extremo superior, con lo que se crea una pequeña bolsa gástrica (volumen de $10-20 \mathrm{ml}$ ) y un orificio estrecho para el paso de los alimentos al resto del estómago. El diámetro de la banda se puede ajustar después de la operación, añadiendo o eliminando suero salino a través de un puerto de acceso subcutáneo, lo que permite regular el tamaño del orificio y la salida de alimentos, para adaptarlos a las necesidades del paciente ${ }^{56}$. El dispositivo Lap-Band es el único aprobado por la FDA para su uso en Estados Unidos.

\section{Gastroplastia vertical en banda o anillada $a^{57,58}$}

Se realiza una partición vertical de la parte superior del estómago, mediante grapas quirúrgicas, siguiendo la curvatura menor, para confeccionar una pequeña bolsa o reservorio (volumen de 10-20 ml), separada del resto del estómago por un pequeño orificio o estoma para la salida de alimentos, de $1 \mathrm{~cm}$ de diámetro, rodeado por una banda externa (no ajustable) de silicona o una anilla para prevenir la dilatación. Puede practicarse por laparoscopia.

Gastrectomía tubular o tubo gástrico 59,60

En esta intervención, se extirpa, por laparoscopia, entre el 60 y el $80 \%$ del estómago, y se conserva una porción vertical alrededor de la curvatura menor, con lo que el remanente gástrico toma la forma de un tubo o manga. Suele realizarse en superobesos (IMC > 50) o en pacientes de alto riesgo quirúrgico como una primera intervención, con la intención de realizar posteriormente una segunda (cruce duodenal $[\mathrm{CD}]$ o $\mathrm{BG})$.

\section{Procedimientos malabsortivos}

La historia de la CB nació con la derivación yeyunoileal y otras formas de bypass intestinal, entre 1950 y $1960^{61}$. Sin embargo, estos procedimientos iniciales, basados en la malabsorción, se abandonaron debido a su tasa inaceptable de complicaciones metabólicas (malnutrición, cirrosis hepática, enfermedad ósea, litiasis renal, etc.) asociadas en su mayoría al síndrome de asa ciega. 


\section{Procedimientos mixtos}

Asocian una derivación gastrointestinal al componente restrictivo gástrico con el objetivo de modificar la fisiología del proceso digestivo y disminuir parcialmente la absorción de nutrientes.

\section{Derivación gástrica o bypass gástrico en " $Y$ " de Roux (preferentemente restrictiva y parcialmente malabsortiva)}

El BG proximal en "Y" de Roux es una de las intervenciones más utilizadas actualmente, debido a la buena evidencia científica disponible sobre su superioridad frente a la gastroplastia vertical en banda (GVB), demostrada en ECA y considerada, por algunos, especialmente en Estados Unidos, el tratamiento quirúrgico de referencia (método de referencia) con el que comparar el resto de procedimientos ${ }^{62-67}$. (Grado de recomendación B)

Los diferentes tipos de BG combinan una partición gástrica para crear una pequeña bolsa gástrica proximal (reservorio inferior a $30 \mathrm{ml}$ ), con una derivación gastroyeyunal y una reconstrucción del tránsito intestinal en "Y" de Roux. Se realiza una sección del yeyuno después del ángulo de Treitz $(50-100 \mathrm{~cm})$, la porción distal del yeyuno se anastomosa al reservorio gástrico (asa de Roux o canal alimentario) y la porción proximal (canal biliar) al yeyuno, a una distancia variable de la anastomosis gastroyeyunal (50$150 \mathrm{~cm}$ ), según el grado de obesidad ${ }^{63,66,68}$. De esta forma se evita el paso de los alimentos por la mayor parte del estómago, el duodeno y el yeyuno proximal, alterando la respuesta neuroendocrina digestiva y acortando el recorrido de los alimentos por el intestino delgado. En varios estudios aleatorizados se ha evaluado el efecto de la longitud del asa de Roux en la pérdida de peso y las secuelas nutricionales ${ }^{69-72}$, y se ha observado que en pacientes con SOM un asa de Roux de $150 \mathrm{~cm}$ produce más pérdida de peso (en comparación con asas más cortas) sin aumento aparente de las complicaciones nutricionales. Por el contrario, en pacientes con OM no hay diferencias en la pérdida de peso con longitudes del asa entre 50 y $150 \mathrm{~cm}$.

\section{Derivación biliopancreática (parcialmente restrictiva y preferentemente malabsortiva)}

Incluye la DBP de Scopinaro et $\mathrm{al}^{73}$ y sus variantes, el $\mathrm{CD}^{74,75}$ y la DBP de $\operatorname{Larrad}^{76}$.

Combinan una gastrectomía parcial (creando una bolsa gástrica mayor que la del BG) con una anastomosis gastroileal (duodenoileal en el CD), un canal alimentario de longitud variable $(250-300 \mathrm{~cm})$, un cortocircuito de las secreciones biliares y pancreáticas hasta el tramo final del intestino delgado (canal biliar) y un canal común a 50-100 cm de la válvula ileocecal, lo que induce maldigestión y malabsorción intestinal (preferentemente de las grasas). Habitualmente, se añade una colecistectomía profiláctica, por el riesgo de desarrollar litiasis biliar.

El CD conserva una porción vertical del estómago alrededor de la curvatura menor, y preserva el píloro y una pequeña porción del duodeno en el canal alimentario, con lo que se evita el síndrome de dumping.

Algunos autores, como Scopinaro et $\mathrm{al}^{73}$, han introducido cambios en las técnicas originales (reducción de la capacidad gástrica, alargamiento del canal alimentario o del canal común), en función del grado de obesidad del paciente y sus hábitos dietéticos. 


\section{Cambios en la cirugía bariátrica: laparoscopia}

En la última década, se ha producido un crecimiento considerable de la CB en todo el mundo, debido principalmente a la implantación progresiva de las técnicas laparoscópicas.

La BGAL fue el primer procedimiento realizado por laparoscopia por Belachew et $\mathrm{al}^{55}$ en 1994. En el mismo año, Wittgrove y Clark $^{77}$ realizaron el primer BG laparoscópico. Varios ECA $^{78-80}$ han aportado datos de las ventajas respecto a la técnica abierta: menor riesgo de eventraciones, infecciones de la herida y complicaciones de pared, menor pérdida sanguínea, menor duración de la hospitalización, menos dolor, menos complicaciones respiratorias y recuperaciones más rápidas, consiguiendo resultados similares en cuanto a pérdida de peso. (Grado de recomendación B)

La laparoscopia se aplicó posteriormente a las técnicas preferentemente malabsortivas (DBP, CD), pero por su dificultad se ha usado en menor escala.

Actualmente, el $63 \%$ de las operaciones bariátricas se realiza por vía laparoscópica ${ }^{34}$, y se considera de primera elección, a menos que haya contraindicaciones específicas ${ }^{81,82}$. Sin embargo, la laparoscopia es técnicamente difícil, requiere experiencia y conlleva una "curva de aprendizaje", por lo que precisa conversión a cirugía abierta hasta en el $23 \%$ de los pacientes en diferentes estudios ${ }^{33,78,83-85}$.

La SECO recomienda que cada equipo desarrolle por esta vía la misma técnica que por laparotomía, aplicando las mismas indicaciones, seleccionando inicialmente los casos más favorables, previa experiencia en cirugía laparoscópica avanzada, habiendo recibido formación previa teoricopráctica y asistencia en sus primeros casos por cirujanos experimentados ${ }^{38}$. (Grado de recomendación D)

\section{Comparación de diferentes técnicas}

\section{Técnicas restrictivas}

La GVB produce una buena pérdida de peso a corto plazo: pérdida de sobrepeso (PSP) de alrededor del $50 \%$ el primer año, 25\% del IMC, con un porcentaje escaso de complicaciones perioperatorias (inferior al 10\%) y una mortalidad baja (igual o inferior al 1\%). Sin embargo, muchos pacientes presentan una reganancia significativa de peso en los años posteriores, con necesidad de reintervención para reconversión quirúrgica hasta en un $40 \%$ de $\operatorname{los} \operatorname{casos}^{81}$, lo que explica en parte la disminución progresiva de su utilización en los últimos años.

La pérdida de peso con la BGAL parece más gradual, con resultados de PSP e IMC perdido similares a la GVB a los 2 años. En el estudio de Nilsell et al ${ }^{86}$, de 2001, se observó que, aunque durante el primer año de seguimiento la pérdida de peso era mayor con GVB, los pacientes con BGAL seguían perdiendo peso durante más tiempo, consiguiendo una reducción de $43 \mathrm{~kg}$ (frente a $35 \mathrm{~kg}$ ) a los 5 años, y un porcentaje mayor estaba satisfecho con la intervención (el 56 frente al 81\%). Sin embargo, en otro estudio más reciente de Morino et al $^{87}$, en el que se realizan ambas técnicas por vía laparoscópica, se observó una pérdida mayor de peso con GVB un año después de la intervención (IMC de 30,1 frente a 35,5) y mejores resultados a los 3 años de seguimiento (sobrepeso inferior al 50\% en el 63\% de GVB frente al $25 \%$ de BGAL, con menos complicaciones tardías). No hay estudios prospectivos bien diseñados a largo plazo en los que se comparen ambos procedimientos, por lo que todavía no se dispone de evidencia suficiente para afirmar que la BGAL es superior a la GVB.

Las tasas de morbilidad y mortalidad perioperatorias (GVB y BGAL) son de un 5 y un $0,1 \%$, respectivamente, en manos expertas ${ }^{34,35}$. 
Un inconveniente de las técnicas restrictivas es que obligan a cambios importantes en los hábitos alimentarios y pueden asociarse a vómitos persistentes e intolerancia a algunos alimentos, lo que limita la calidad de vida, así como a alteraciones de la conducta alimentaria, al dirigir las preferencias de los pacientes hacia alimentos líquidos hipercalóricos, lo cual favorece la reganancia de peso ${ }^{65}$.

\section{Técnicas mixtas}

La PSP en los pacientes sometidos a BG varía entre un 60 y un $75 \%$ el primer año postoperatorio (alrededor de un 35\% de IMC), con una ligera reganancia de 3-5 años después de la intervención ${ }^{33,38,88}$, pero con un mantenimiento mejor a largo plazo del peso perdido en relación con los procedimientos restrictivos. En el estudio $\mathrm{SOS}^{32}$, la pérdida de peso a los 10 años con el BG (el $6 \%$ del grupo quirúrgico) fue del $25 \%$, frente a un $16,1 \%$ con las técnicas restrictivas (gastroplastias y bandas gástricas ajustables y no ajustables). Otros estudios comparativos entre BG y GVB ${ }^{62,64-66}$ demuestran también una pérdida de peso significativamente mayor con el BG a corto y medio plazo, y resultados superiores en la evolución de algunas comorbilidades, como la DM tipo 2 (DM2), la HTA, la dislipemia y el SAOS. (Grado de recomendación $B$ )

Por el contrario, en el metaanálisis de Buchwald et $\mathrm{al}^{34}$, la pérdida de peso fue superior con la GVB que con el BG.

Según el metaanálisis de Maggard et $\mathrm{al}^{35}$, varios estudios comparativos recientes entre BG y BGAL parecen indicar que, mientras que la pérdida de peso es superior tras el BG durante los primeros 2-3 años, a partir del cuarto y el quinto años las curvas de pérdida de peso de ambos procedimientos se hacen similares. La confirmación de estos datos a largo plazo podría reforzar el papel de la BGAL en el tratamiento quirúrgico de la obesidad.

La incidencia de complicaciones perioperatorias ha mejorado sustancialmente en la última década, con unas tasas de morbilidad y mortalidad inferiores a un 10 y un $1 \%$, respectivamente ${ }^{34,35,83}$.

El BG puede producir síndrome de dumping (rubefacción facial, palpitaciones, mareo, sudoración y diarrea) como resultado del rápido vaciamiento de la bolsa gástrica en el yeyuno, e hipoglucemia reactiva (dumping tardío) de 90 a 120 min después de la ingesta de azúcares simples, con una incidencia variable, del 20 al 60\%. Este efecto favorece la hiporexia postoperatoria y la aversión por los dulces que presentan muchos de los pacientes sometidos a BG, y sería la causa, al menos en parte, de los mejores resultados con respecto a las técnicas restrictivas ${ }^{62}$.

Entre los inconvenientes del BG con respecto a las técnicas restrictivas están su mayor complejidad y riesgo mayor de mortalidad, su irreversibilidad, la dificultad de acceso diagnóstico al estómago excluido y la malabsorción de micronutrientes, fundamentalmente hierro, vitamina $\mathrm{B}_{12}$, calcio y ácido fólico. No suele producir malnutrición proteica ${ }^{90}$.

Las diferentes técnicas de DBP, diseñadas para evitar las complicaciones del bypass yeyunoileal y el síndrome de asaciega, producen los mejores resultados de pérdida de peso a largo plazo ${ }^{34,35,38}$, pero presentan más riesgo de malnutrición proteica y otras secuelas nutricionales potencialmente graves, por lo que es imprescindible un seguimiento postoperatorio atento.

Con la DBP y sus variantes, se ha publicado una PSP superior al 70\% (el 35,5\% de IMC perdido), con excelente mantenimiento de éste durante 18 años en la serie de Scopinaro et $\mathrm{al}^{73}$ de más de 2.000 pacientes. La incidencia de complicaciones oscila entre el 10 y el 15\%, con una tasa de mortalidad del 1$3 \%{ }^{88}$. Sin embargo, los resultados de los estudios con DBP y CD se basan en series de casos clínicos y no hay estudios aleatorizados frente al BG, por lo que el nivel de evidencia científica es menor. (Grado de recomendación $C$ ) 
Estas técnicas conllevan menos restricciones alimentarias, pero pueden producir diarrea (con potenciales problemas perianales secundarios), flatulencia y heces malolientes, lo que limitan la vida de relación social ${ }^{38,91}$.

Las complicaciones nutricionales postoperatorias incluyen anemia ferropénica, déficit de vitamina $\mathrm{B}_{12}$ (con menos frecuencia que el BG al tener un mayor volumen gástrico), enfermedad ósea metabólica por malabsorción de calcio y vitamina $\mathrm{D}$, deficiencia sintomática de otras vitaminas liposolubles y malnutrición proteica con necesidad de hospitalización para soporte nutricional. Estas complicaciones suelen ser reversibles con modificaciones dietéticas y suplementos adecuados ${ }^{73,74}$.

Estos procedimientos están indicados en pacientes con SOM, sobre todo en aquellos con un IMC > 55 , en los que es previsible que el BG no funcione ${ }^{38,91}$.

\section{Efecto de la cirugía bariátrica en las comorbilidades de la obesidad}

\section{Mortalidad}

Los datos disponibles sobre reducción de la mortalidad son escasos. Dos estudios recientes ${ }^{92,93}$ han mostrado que la CB disminuye la mortalidad a largo plazo, la morbilidad y la necesidad de cuidados médicos.

\section{Diabetes mellitus}

Hay múltiples estudios que muestran una mejoría o un buen control de la DM2 y la intolerancia a la glucosa en muchos de los pacientes intervenidos, más evidente con los procedimientos derivativos que con los restrictivos ${ }^{32,94-96}$ : el 98,8\% para la DBP, el $83,7 \%$ para el BG, el 71,6\% para la GVB y el $47,9 \%$ para la $\mathrm{BGAL}^{34}$. (Grados de recomendación A y $B$ )

En los pacientes diabéticos intervenidos mediante BG, se ha publicado, además, una disminución del riesgo de complicaciones crónicas, como la neuropatía ${ }^{97}$, y de mortalidad por episodios cardiovasculares $^{98}$.

El control de la DM en los procedimientos que asocian un componente derivativo ocurre rápidamente (incluso días después de la intervención), antes de que se produzca una pérdida significativa de peso. Esta observación ha desencadenado múltiples investigaciones sobre el papel de las hormonas gastrointestinales en la resistencia a la insulina y la fisiopatología de la DM2 $2^{99}$.

\section{Hipertensión arterial}

La pérdida de peso inducida por la CB se asocia a mejoría de la HTA, e incluso a normalización de las cifras de PA de forma proporcional a la cantidad de peso perdido (independientemente de la técnica quirúrgica). (Grado de recomendación $B$ )

Según la revisión de Buchwald et $\mathrm{al}^{34}$, los pacientes hipertensos presentan una tasa de buen control de la HTA después de la pérdida quirúrgica de peso del $62 \%$ y una tasa combinada de buen control o mejoría del $78,5 \%$. La PA puede normalizarse también, aunque no se alcance el peso ideal ${ }^{100}$. En los pacientes que no consiguen normalizar las cifras de PA suelen reducirse las necesidades de medicación antihipertensiva. 
En el estudio $\operatorname{SOS}^{32}$, la tasa de recuperación de la HTA a los 2 y los 10 años fue mayor para los individuos tratados con cirugía que para el grupo control. Se debe señalar que la tasa de incidencia de HTA a los 2 y los 10 años no se modificó con la cirugía restrictiva (un 94\% de los casos intervenidos) pero disminuyó con los procedimientos de BG.

\section{Dislipemia}

Múltiples estudios han encontrado una mejoría significativa del perfil lipídico después de CB en más del 70\% de pacientes ${ }^{32,34,35,101-104}$. (Grado de recomendación B)

Con el BG pueden obtenerse reducciones del $40 \%$ en los triglicéridos y del $25 \%$ en el colesterol total a los 6-12 meses de la intervención ${ }^{101}$. El estudio SOS $^{32}$ observó mejorías en los triglicéridos y en el colesterol unido a lipoproteínas de alta densidad (cHDL) en el grupo quirúrgico a los 2 y los 10 años. En general, la dislipemia parece mejorar más con los procedimientos mixtos (malabsortivos), aunque el cHDL mejora también con los procedimientos restrictivos ${ }^{34}$. En un estudio reciente prospectivo y aleatorizado en 130 pacientes, en el que se comparó DBP con $\mathrm{BG}^{105}$, se demostró una mayor disminución de la cifras de colesterol con el primer procedimiento.

\section{Episodios cardiovasculares}

No hay datos de ensayos controlados acerca del efecto de la CB en la incidencia de episodios cardiovasculares. Sin embargo, los datos descritos previamente muestran que la CB es efectiva en los factores de riesgo de enfermedad cardiovascular. Hay evidencias de que la pérdida quirúrgica de peso mejora la salud cardiovascular, no sólo por los cambios favorables en los factores de riesgo, sino por mejoría directa de la función ventricular ${ }^{106}$.

\section{Síndrome de apnea del sueño}

Los síntomas relacionados con el SAOS mejoran tras la $\mathrm{CB}^{107-109}$. En el metaanálisis de Buchwald et $\mathrm{al}^{34}$, se observó que los síntomas de SAOS mejoraron significativamente en todos los procedimientos quirúrgicos, con una resolución completa en el $85,7 \%$ de los pacientes afectados. (Grado de recomendación $B$ )

\section{Artropatía degenerativa}

El BG ha demostrado mejorar los síntomas de la enfermedad articular degenerativa en caderas, rodillas, pies y raquis ${ }^{110}$. (Grado de recomendación B)

La artroplastia puede ser difícil o estar contraindicada en individuos con OM. La CB permite conducir a estos pacientes a un rango de peso seguro y efectivo para la cirugía de reemplazamiento articular ${ }^{111}$.

\section{Complicaciones de la cirugía bariátrica}

\section{Mortalidad}

En el metaanálisis de Monteforte y Turkelson ${ }^{83}$, en el que se analiza a más de 3.000 pacientes, se obtuvo una mortalidad combinada de $0,14 \%$ para los procedimientos restrictivos y de $0,3 \%$ para el $\mathrm{BG}$. En el metaanálisis de Buchwald et $\mathrm{al}^{34}$, se encontró una tasa de mortalidad de $0,1 \%$ tras BGAL comparada con un $0,5 \%$ tras $\mathrm{BG}$ y un $1,1 \%$ tras $\mathrm{CD}$. La revisión de Chapman situó la tasa de mortalidad 
de la BGAL en un $0,05 \%^{112}$, pudiendo considerarse actualmente el procedimiento más seguro. (Grado de recomendación $B$ y $C$ )

Las causas más comunes de mortalidad perioperatoria (un $80 \%$ de los casos) ${ }^{35}$ incluyen:

- TVP con TEP secundaria.

- Sepsis abdominal secundaria a fuga de la anastomosis.

- Complicación cardíaca o respiratoria.

La TEP ocurre en, aproximadamente, un $2 \%$ de los pacientes intervenidos, incluso con profilaxis adecuada, y presenta una mortalidad del $15-35 \%$.

La incidencia de fugas anastomóticas varía entre el 1 y el 8\%, con una mortalidad del 10-15\%, existiendo más riesgo de aparición en las intervenciones por laparoscopia (en relación con la curva de aprendizaje $)^{84}$.

Los factores que predicen un riesgo aumentado de mortalidad se relacionan con el tipo de procedimiento, la edad avanzada, el peso preoperatorio, el sexo masculino y la experiencia del cirujano. (Grado de recomendación B)

Algunas comorbilidades, como la DM, la HTA y el SAOS, se han identificado también como predictores preoperatorios de riesgo ${ }^{43}$. (Grado de recomendación $C$ )

La introducción de las técnicas laparoscópicas ha llevado a una disminución sustancial del riesgo de complicaciones relacionadas con la herida (infecciones, seromas, dehiscencia o hernias de pared) ${ }^{33-35,91,112}$. (Grado de recomendación B)

\section{Complicaciones postoperatorias tempranas (30 días)}

- Fuga de la anastomosis, infección secundaria a la fuga.

- Perforación intestinal.

- Infección de la herida quirúrgica u otra infección.

- Absceso intraabdominal.

- Lesión/rotura del bazo.

- TVP, TEP.

- Otras complicaciones pulmonares:

a) Atelectasia.

b) Neumonía.

c) Parada respiratoria secundaria a SAOS.

d) Síndrome de distrés respiratorio agudo.

- Edema agudo de pulmón.

- Complicaciones gastrointestinales:
a) Hemorragia.
b) Úlcera.
c) Estenosis, obstrucción de la anastomosis.
d) Obstrucción del intestino delgado.
e) Disfagia.
f) Deshidratación. 


\section{Complicaciones postoperatorias tardías (más de 30 días)}

- Estenosis u obstrucción del estoma o de la anastomosis.

- Úlcera gastrointestinal (boca anastomótica).

- Colelitiasis.

- Pancreatitis.

- Hernia incisional o eventración.

- Hernia interna.

- Dilatación de la bolsa.

- Disfagia.

- Reflujo gastroesofágico.

- Vómitos.

- Diarrea.

- Deficiencias nutricionales.

- Colgajos de la piel.

- Fracaso de la pérdida de peso o reganancia del peso perdido.

- Complicaciones psicológicas (depresión, interrupción de las relaciones sociales).

\section{Complicaciones nutricionales}

\section{Técnicas restrictivas}

Al no modificar la fisiología digestiva, presentan un riesgo nutricional menor a largo plazo ${ }^{113,114}$, pero exigen cambios importantes en los hábitos alimentarios. Las limitaciones impuestas por la pequeña capacidad de la bolsa gástrica y el diámetro del estoma obligan a tomas muy fraccionadas de pequeñas cantidades de comida blanda, triturada y bien masticada, por lo que pueden asociarse a vómitos e intolerancia a algunos alimentos (como la carne) y alterar la conducta alimentaria postoperatoria, dirigiendo las preferencias a alimentos líquidos de alta densidad calórica ${ }^{62,91}$.

La presencia de complicaciones nutricionales suele ser secundaria a problemas técnicos, dietas excesivamente restrictivas y vómitos repetidos, pudiendo producir secuelas neurológicas e, incluso, malnutrición proteica.

\section{Técnicas mixtas}

El estómago es importante para la producción de ácido clorhídrico (esencial para la absorción apropiada de hierro y factor intrínseco, necesario a su vez para la absorción de vitamina $\mathrm{B}_{12}$ ). El BG y la DBP (y variantes) comportan un riesgo mayor de anemia y otras complicaciones nutricionales ${ }^{113-117}$, al excluir del paso de alimentos a gran parte del estómago, la totalidad del duodeno y una porción variable de yeyuno. Todo ello repercutirá en la absorción de hierro, vitamina $B_{12}$ (principalmente por falta de biodisponibilidad de factor intrínseco), ácido fólico, calcio y otros micronutrientes.

Las deficiencias de hierro y vitamina $\mathrm{B}_{12}$ son las más comunes. Además de la malabsorción, su aparición está favorecida por la intolerancia frecuente a alimentos ricos en estos nutrientes (carnes "rojas"). No suelen responder al suplemento rutinario, por lo que precisan suplementos específicos.

Las técnicas preferentemente malabsortivas (DBP y variantes, BG distal) pueden producir, con mayor frecuencia que el BG, deficiencia de vitamina D y de otras vitaminas liposolubles (A, E, K), debido a la mezcla retrasada y defectuosa del bolo alimenticio con las secreciones biliares y pancreáticas en el tramo final del intestino delgado (canal común) y también malnutrición proteica, como resultado de diarrea persistente, problemas relacionados con la técnica quirúrgica y/o mala adherencia al tratamiento ${ }^{113,114}$. 


\section{Selección de la técnica quirúrgica}

Las características que debería cumplir la técnica "ideal" "11,118 serían:

- Segura (mortalidad menor del 1\%, morbilidad menor del 10\%).

- Útil para al menos el $75 \%$ los pacientes (PSP > 50\% e IMC < 35).

- Duradera (persistencia del beneficio obtenido más de 5 años o ilimitado).

- Reproducible (por la mayoría de cirujanos, fácil curva de aprendizaje).

- Con escasas complicaciones a largo plazo (índice de reintervenciones por debajo del $2 \%$ anual).

- Con buena calidad de vida (sin intolerancias alimentarias, vómitos ni diarrea).

- Con pocos efectos secundarios (sin deficiencias nutricionales).

- Reversible (al menos funcionalmente).

La técnica ideal no exigiría la colaboración por parte del paciente y su eficacia a largo plazo sería independiente de éste.

Desafortunadamente, no existe el tratamiento quirúrgico ideal. Cada enfoque tiene ventajas e inconvenientes (tabla 8), pero en cualquier caso exige al paciente controlar su ingesta de por vida, hacer ejercicio diariamente, tomar suplementos orales y/o parenterales a largo plazo y mantener el seguimiento una vez estabilizada la pérdida de peso. Por tanto, la elección debe individualizarse, dependiendo de la experiencia del equipo quirúrgico y las características del paciente. 
TABLA 8. Ventajas e inconvenientes de las técnicas quirúrgicas más utilizadas

\begin{tabular}{|c|c|c|c|c|c|}
\hline & Ventajas & Inconvenientes & Complicaciones & PSP & Indicaciones \\
\hline BGAL & $\begin{array}{l}\text { Vía laparoscópica } \\
\text { Menor riesgo de mortalidad } \\
\text { Menor estancia hospitalaria } \\
\text { Rápida recuperación } \\
\text { Procedimiento reversible } \\
\text { Banda ajustable } \\
\text { Buena absorción de nutrientes } \\
\text { Bajo riesgo de síndrome de } \\
\text { dumping }\end{array}$ & $\begin{array}{l}\text { Náuseas, vómitos } \\
\text { Manipulación del } \\
\text { reservorio } \\
\text { Coste elevado } \\
\text { Contraindicada en } \\
\text { trastornos motores } \\
\text { de esófago }\end{array}$ & $\begin{array}{l}\text { Intraoperatorias } \\
\text { Hemorragia } \\
\text { Necesidad de conversión a } \\
\text { procedimiento abierto } \\
\text { Lesión esplénica gástrica o } \\
\text { esofágica } \\
\text { Postoperatorias } \\
\text { Deslizamiento de la banda } \\
\text { (prolapso gástrico) } \\
\text { Fuga del balón o el tubo } \\
\text { Infecciones del puerto } \\
\text { Infecciones de la banda } \\
\text { Tardías } \\
\text { Erosión o inclusión de la } \\
\text { banda en el estómago } \\
\text { Dilatación esofágica }\end{array}$ & $50 \%$ & $\begin{array}{l}\text { IMC }<45 \\
\text { Jóvenes } \\
\text { Alta capacidad de } \\
\text { colaboración }\end{array}$ \\
\hline $\begin{array}{l}\text { DBP y } \\
\text { variantes }\end{array}$ & $\begin{array}{l}\text { Menor restricción alimentaria } \\
\text { Buena calidad de vida } \\
\text { Más pérdida de peso } \\
\text { Posibilidad de vía } \\
\text { laparoscópica }\end{array}$ & $\begin{array}{l}\text { Diarrea-esteatorrea } \\
\text { Síndrome de } \\
\text { dumping } \\
\text { Más riesgo de } \\
\text { deficiencias } \\
\text { nutricionales } \\
\text { Contraindicada en } \\
\text { enfermedad hepática }\end{array}$ & $\begin{array}{l}\text { Úlcera marginal } \\
\text { Déficit nutricionales } \\
\text { Malabsorción de vitaminas } \\
\text { liposolubles (A, D, E, K) } \\
\text { Deficiencias de } \\
\text { micronutrientes (hierro, } \\
\text { calcio, otros) } \\
\text { Malnutrición proteica } \\
\text { Hiperparatiroidismo } \\
\text { secundario } \\
\text { Colelitiasis }\end{array}$ & $\begin{array}{l}70- \\
85 \%\end{array}$ & $\begin{array}{l}\text { A partir de IMC } \\
>45 \\
\text { Muy útil en } \\
\text { super- } \\
\text { superobesos } \\
(\text { IMC > 60) }\end{array}$ \\
\hline
\end{tabular}

BG: bypass gástrico; BGAL: banda gástrica ajustable laparoscópica; BGlap: bypass gástrico laparoscópico; DBP: derivación biliopancreática; IMC: índice de masa corporal.

Modificado de ASBS (www.asbs.org) y Díez del Val et al ${ }^{91}$ 
Los mecanismos íntimos implicados en la pérdida postoperatoria de peso no se conocen bien. Además de la limitación en la ingesta calórica y de la malabsorción, los cambios neuroendocrinos inducidos por el componente derivativo pueden contribuir directamente al efecto anorexígeno de la intervención ${ }^{119-123}$ y a la mejoría de las comorbilidades metabólicas preoperatorias $9^{4,99}$, al alterar el patrón de secreción de diferentes hormonas gastrointestinales implicadas en la regulación del peso corporal y del metabolismo energético y en la respuesta insulínica posprandial. Estos factores ayudarían a explicar la superioridad de los procedimientos mixtos sobre los restrictivos en cuanto a pérdida de peso y control de las complicaciones metabólicas, especialmente la DM2.

En la tabla 9 se resumen los factores que hay que tener en cuenta al seleccionar el tipo de intervención. En pacientes hiperfágicos (comedores de raciones abundantes), sin SOM, con pocas comorbilidades y con capacidad de adaptación a las limitaciones de la ingesta, pueden ser suficientes las técnicas restrictivas. En presencia de SOM, DM, dislipemia o desestructuración del patrón alimentario, son preferibles las técnicas que asocien un componente derivativo. (Grados de recomendación $B$ y $C$ )

TABLA 9. Factores a tener en cuenta al seleccionar el tipo de operación

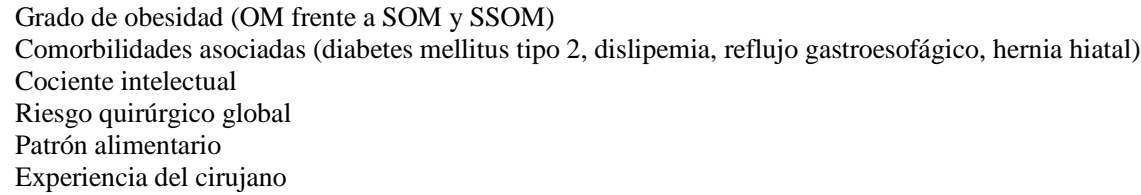

OM: obesidad mórbida; SOM: superobesidad mórbida; SSOM: super-superobesidad mórbida

Asimismo, el reflujo gastroesofágico y las alteraciones motoras del esófago son contraindicaciones para realizar procedimientos restrictivos.

\section{Valoración de resultados de la cirugía bariátrica a largo plazo}

Uno de los principales problemas al evaluar el efecto del tratamiento quirúrgico es la dificultad para comparar las distintas intervenciones, debido a la heterogeneidad en la medida de los resultados y la variabilidad en la duración del seguimiento postoperatorio ${ }^{124}$, así como la escasez de $\mathrm{ECA}^{33}$.

\section{Variables de resultados}

El análisis debería incluir las variables siguientes, y al menos 5 años de seguimiento postoperatorio $^{2,125}$ :

1.Variables de eficacia:

- Pérdida de peso.

- Evolución de índices ponderales y antropométricos.

- Resolución o mejoría de las comorbilidades previas.

2.Variables de seguridad:

- Morbimortalidad perioperatoria.

- Morbilidad postoperatoria a largo plazo.

- Complicaciones nutricionales.

3.Medidas objetivas de calidad de vida y satisfacción del paciente.

\section{(Grado de recomendación B)}


Teniendo en cuenta la importancia de la homogeneidad en los criterios de valoración de resultados, es recomendable adoptar un sistema estandarizado. Muchos de estos aspectos se contemplan en el sistema de evaluación y análisis bariátrico BAROS (Bariatric Analysis and Reporting Outcome System ${ }^{126}$ ) (tabla 10), el único disponible actualmente para estudiar 4 aspectos importantes de resultados tras CB: pérdida de peso (expresada como PSP), mejoría de comorbilidades, desarrollo de complicaciones, necesidad de reintervención y cambios en la calidad de vida (aspecto que se ha modificado y validado recientemente, incluyendo un ítem relacionado con la alimentación) ${ }^{127}$. El fallo o el éxito de la intervención se basan en la puntuación global sumando los 4 tipos de resultados.

Las medidas de evaluación deberían realizarse al conjunto de pacientes al menos cada 5 años, porque nos permiten tener datos objetivos a largo plazo y establecer comparaciones entre diferentes grupos de trabajo $^{125}$.

TABLA 10. Sistema de evaluación BAROS actualizado

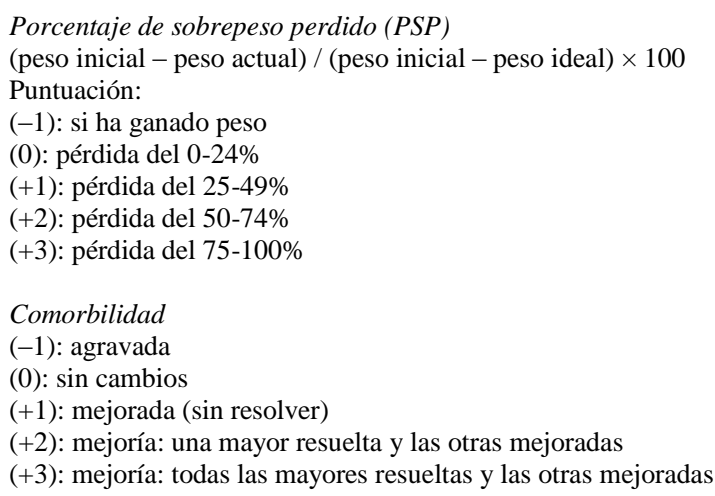

Adaptada de Oria et $\mathrm{al}^{126}$ y Moorehead et $\mathrm{al}^{127}$.

BAROS: Bariatric Analysis and Reporting Outcome System. 
Los parámetros utilizados incluyen el peso perdido en kilogramos (que no se considera una buena medida), el porcentaje de peso inicial perdido (PIP), el porcentaje de exceso de peso o sobrepeso perdido (PSP) y el descenso del IMC (en términos absolutos o como porcentaje) ${ }^{2,38,125}$.

La mayoría de las recomendaciones incluye como criterio de éxito una pérdida de al menos un 50\% de PSP. El IMC es probablemente la mejor medida para valorar los resultados de pérdida de peso, aunque tenga una correlación indirecta con la masa grasa (la determinación de la grasa corporal con bioimpedancia quizá podría ofrecer resultados más válidos). Se acepta que un IMC final igual o superior a 35 es un resultado insuficiente ${ }^{125}$. (Grado de recomendación D)

TABLA 11. Fórmulas para calcular la pérdida de peso

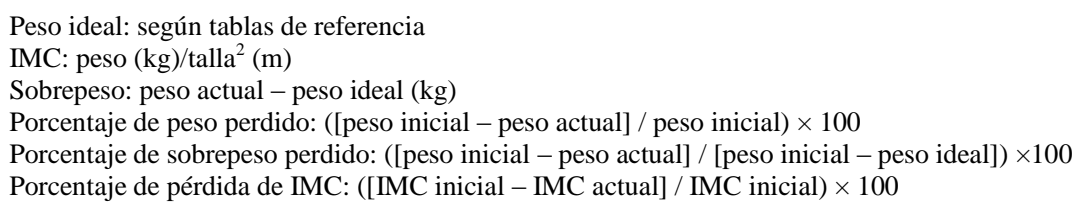

IMC: índice de masa corporal.

\section{Calidad de vida relacionada con la salud}

Proporciona una importante información, basada en parámetros objetivos, sobre el impacto que produce la enfermedad en el paciente y sobre el efecto del tratamiento, valorando no sólo los factores biológicos, sino también los psicológicos y sociales.

En pacientes con OM se pueden utilizar 2 tipos de cuestionarios para medir la calidad de vida relacionada con la salud: genéricos y específicos para obesidad.

Los cuestionarios genéricos validados para su uso en español incluyen, entre otros, el SF-36 ${ }^{128}$, el Nottingham Health Profile (38 ítems) ${ }^{129}$ y el GIQLI ${ }^{130}$. El SF-36 es el más utilizado; consta de 36 preguntas distribuidas en 8 dimensiones de salud. Cada pregunta se responde con una escala, estandarizada de 0 a 100 (de peor a mejor salud). El GIQLI, centrado en la presencia de síntomas gastrointestinales, se ha utilizado recientemente en España en pacientes con OM candidatos a $\mathrm{CB}^{131}$.

Los cuestionarios específicos son más sensibles para detectar cambios tras una intervención terapéutica, por lo que tienen gran utilidad clínica. En español disponemos del Moorehead-Ardelt (6 ítems: autoestima, actividad física, vida social, actividad laboral, relaciones sexuales, alimentación) ${ }^{127}$, un cuestionario sencillo específico de CB que forma parte del BAROS. 


\section{SEGUIMIENTO POSTOPERATORIO}

La CB presenta riesgo de morbimortalidad asociada a complicaciones técnicas, nutricionales e, incluso, psiquiátricas, lo que hace imprescindible un seguimiento postoperatorio atento por parte de un equipo hospitalario multidisciplinario, no sólo para detectar tempranamente la aparición de complicaciones, sino también para analizar y mejorar los resultados del tratamiento ${ }^{33,83,113}$.

\section{Educación nutricional}

Las modificaciones anatómicas y/o fisiológicas producidas por las distintas intervenciones alteran de forma variable el proceso digestivo y obligan a cambios permanentes de los hábitos alimentarios y a la toma de suplementos vitamínicos y minerales, por lo que se debe proporcionar en primer lugar, y desde el período preoperatorio, un programa de educación nutricional que ayude a los pacientes (y a sus familiares) a comprender y aceptar estos cambios, con el fin de facilitar la tolerancia digestiva, conseguir una buena adherencia al tratamiento y prevenir la aparición de complicaciones en el postoperatorio ${ }^{132}$. (Grado de recomendación D)

\section{Calendario de seguimiento médico (tabla 12)}

Deben programarse revisiones periódicas en las consultas de endocrinología/nutrición, cirugía y psiquiatría, si es posible el mismo día. La frecuencia de las visitas se ajustará al tiempo transcurrido desde la intervención, las enfermedades asociadas y la evolución clínica del paciente. Como orientación, el calendario de seguimiento (en ausencia de complicaciones) incluirá revisiones en los meses 1, 3, 6, 12, 18,24, y después anualmente ${ }^{133}$. (Grado de recomendación D)

En caso de complicaciones postoperatorias, puede ser necesaria la valoración por otros servicios, como gastroenterología, neumología, cardiología, rehabilitación o cirugía plástica.

TABLA 12. Seguimiento médico recomendado después de cirugía bariátrica. Individualizar según técnica, evolución clínica y complicaciones

\begin{tabular}{|c|c|c|c|c|c|c|c|c|}
\hline & $1 \mathrm{mes}$ & 3 meses & 6 meses & 12 meses & 18 meses & 24 meses & Anualmente & A los 5 años \\
\hline Antropometría $^{a}$ & $\mathrm{x}$ & $\mathrm{x}$ & $\mathrm{x}$ & $\mathrm{x}$ & $\mathrm{x}$ & $\mathrm{x}$ & $\mathrm{x}$ & \\
\hline Tolerancia digestiva & $\mathrm{x}$ & $\mathrm{x}$ & $\mathrm{x}$ & $\mathrm{x}$ & $\mathrm{x}$ & $\mathrm{x}$ & $\mathrm{x}$ & \\
\hline Cumplimiento del tratamiento & $\mathrm{x}$ & $\mathrm{x}$ & $\mathrm{x}$ & $\mathrm{x}$ & $\mathrm{x}$ & $\mathrm{x}$ & $\mathrm{x}$ & \\
\hline Analítica $^{\mathrm{b}}$ & $\mathrm{x}$ & $\mathrm{x}$ & $\mathrm{x}$ & $\mathrm{x}$ & $\mathrm{x}$ & $\mathrm{x}$ & $\mathrm{x}$ & \\
\hline $25 \mathrm{OH}-\mathrm{D}_{3}$ & & & $\mathrm{x}$ & $\mathrm{x}$ & $\mathrm{x}$ & $\mathrm{x}$ & $\mathrm{x}$ & \\
\hline PTHi & & & $\mathrm{x}$ & $\mathrm{x}$ & $\mathrm{x}$ & $\mathrm{x}$ & $\mathrm{x}$ & \\
\hline DMOc & & & & $\mathrm{x}$ & & $\mathrm{x}$ & $\mathrm{x}$ & \\
\hline Complicaciones & $\mathrm{x}$ & $\mathrm{x}$ & $\mathrm{x}$ & $\mathrm{x}$ & $\mathrm{x}$ & $\mathrm{x}$ & $\mathrm{x}$ & \\
\hline Comorbilidades & & $\mathrm{x}$ & $\mathrm{x}$ & $\mathrm{x}$ & $\mathrm{x}$ & $\mathrm{x}$ & $\mathrm{x}$ & \\
\hline Calidad de vida & & & & $\mathrm{x}$ & & $\mathrm{x}$ & $\mathrm{x}$ & \\
\hline Resultados & & & & & & & & $\mathrm{x}$ \\
\hline
\end{tabular}

25OH-D ${ }_{3}$ : calcifediol; DMO: densitometría ósea; PTHi: hormona paratiroidea intacta.

a Antropometría: peso, índice de masa corporal, porcentaje de peso perdido, porcentaje de sobrepeso perdido, cintura y cadera, índice cintura/cadera.

b Analítica: hemograma completo, coagulación, bioquímica con perfil hepático, ferritina, ácido fólico, vitamina $\mathrm{B}_{12}$, calcio, magnesio, cinc, albúmina, transferrina, calciuria.

${ }^{\mathrm{c}} \mathrm{Si}$ la DMO es baja o en descenso a los 24 meses, medir DMO anualmente. 


\section{Protocolo de seguimiento (tabla 13)}

En cada revisión se analizarán:

1. Pérdida de peso (evolución de índices ponderales y parámetros antropométricos).

2. Tolerancia digestiva (adaptación a la dieta, hábitos alimentarios, posibles intolerancias, vómitos, dolor abdominal, diarrea).

3. Parámetros nutricionales (clínicos, analíticos).

4. Cumplimiento terapéutico (plan de alimentación, toma de suplementos, actividad física).

5. Evolución de comorbilidades preoperatorias (DM, HTA, SAOS, etc.).

6. Aparición de complicaciones (técnicas, nutricionales, psiquiátricas).

7. Calidad de vida.

(Grados de recomendación A y D)

TABLA 13. Componentes del seguimiento postoperatorio

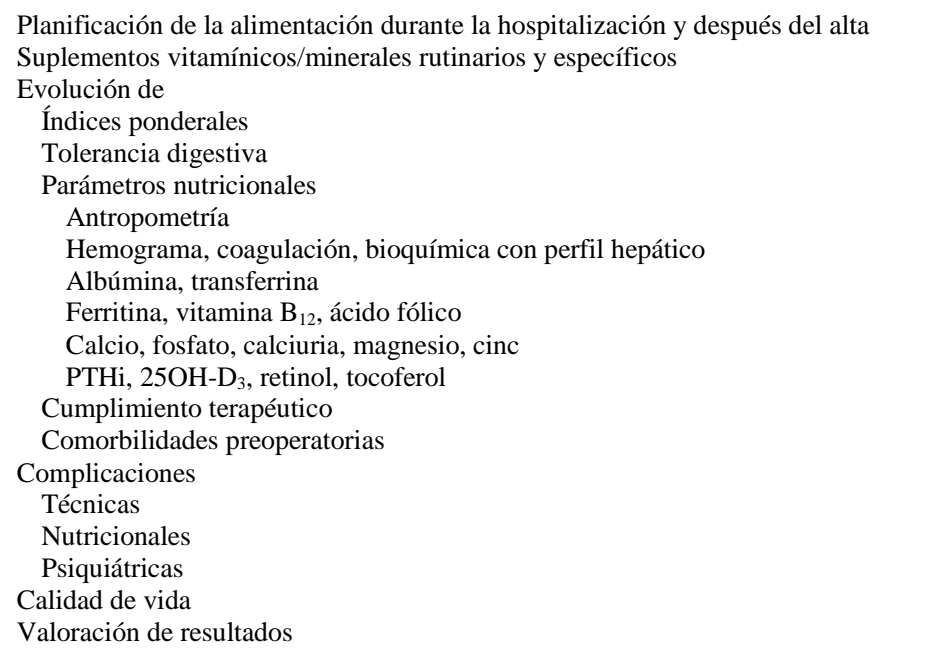

25OH-D ${ }_{3}$ : calcifediol; PTHi: hormona paratiroidea intacta.

\section{Fases del seguimiento}

A efectos prácticos, se recomienda dividir el seguimiento médico en 3 etapas ${ }^{133}$ :

1. Período perioperatorio: hospitalización. Primer mes postoperatorio.

2. Período postoperatorio temprano, de pérdida de peso: del segundo mes a los 12-18 meses.

3. Período postoperatorio tardío: tras la estabilización del peso corporal. Duración indefinida. 


\section{Período perioperatorio}

Además de apoyar al servicio de cirugía en la detección y el tratamiento de posibles complicaciones quirúrgicas (fugas anastomóticas, hemorragia aguda, TEP, infección de la herida quirúrgica, otras infecciones, descompensación de enfermedades previas), el seguimiento médico estará centrado en planificar el tratamiento nutricional durante la hospitalización y las primeras semanas después del alta.

\section{Reintroducción de la alimentación (tabla 14)}

Debe ser progresiva, con transición por fases bien definidas desde una dieta líquida muy fraccionada, hasta una dieta sólida, en uno o 2 meses, según el grado de tolerancia digestiva y el tipo de intervención (en general, el período de adaptación será más prolongado cuanto mayor sea el componente restrictivo) ${ }^{65}$. Esta progresión tiene por finalidad conseguir una buena consolidación de las suturas y favorecer el aprendizaje de los nuevos hábitos alimentarios.

TABLA 14. Planificación de la alimentación

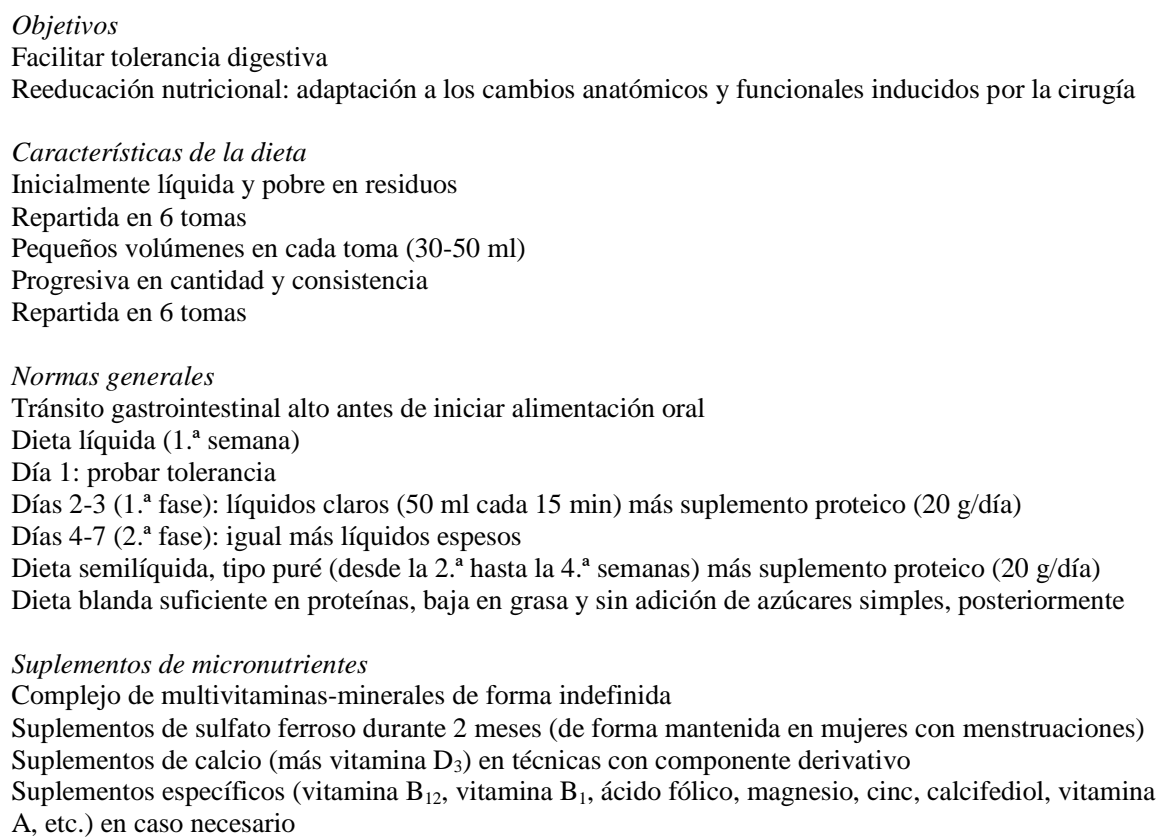

Cada centro dispondrá de dietas protocolizadas para el postoperatorio de $\mathrm{CB}$, que facilitará y explicará a los pacientes y sus familiares al reiniciar la alimentación oral.

Durante la primera fase (primera semana de dieta líquida), la alimentación se fraccionará en múltiples tomas de pequeño volumen (unos $50 \mathrm{ml}$ ).

La ingesta calórica diaria, generalmente inferior a $1.000 \mathrm{kcal}$, es insuficiente para cubrir los requerimientos calóricos y proteicos (estimados en $1-1,5 \mathrm{~g} / \mathrm{kg} / \mathrm{día})^{134}$, por lo que se recomienda consumir un mínimo de $750 \mathrm{ml} /$ día de leche o yogur líquido y un suplemento hiperproteico bajo en calorías o un módulo proteico que aporte unos $20 \mathrm{~g}$ /día de proteínas adicionales, hasta finalizar el período de transición. En caso de intolerancia a la lactosa, puede ser útil administrar leche sin lactosa o sustituir la leche por una fórmula de nutrición enteral completa hiperproteica y normocalórica o hipocalórica, como 
VEGEfast ${ }^{\circledR}$ Complet $\left(7,8 \mathrm{~g}\right.$ de proteínas/100 ml), VEGEfast ${ }^{\circledR}$ Diet $(7,4 \mathrm{~g} / 100 \mathrm{ml})$ u Optisource® $(7,5$ $\mathrm{g} / 100 \mathrm{ml})$.

La dieta líquida (pobre en residuos) favorece el estreñimiento, que debe prevenirse o combatirse con las medidas habituales, teniendo la precaución de no administrar laxantes osmóticos (tipo lactulosa) en las técnicas de derivación gastrointestinal, por la posibilidad de inducir un síndrome de dumping ${ }^{135}$.

Después de la primera semana (intervenciones mixtas) o del primer mes (intervenciones restrictivas), se progresará a la segunda fase (dieta semilíquida o tipo puré), más o menos espesa según la tolerancia del paciente. Además de la leche, se introducirán proteínas en forma de carne blanca, pescado blanco o huevos, triturados junto con los hidratos de carbono y las grasas. Como alternativa (comidas fuera de casa), pueden consumirse alimentos comerciales de textura modificada para adultos. En caso de intolerancia a la carne o al pescado, se añadirá al puré un módulo proteico, o éste se sustituirá por una fórmula completa hiperproteica hipocalórica (VEGEfast ${ }^{\circledR}$ Complet, VEGEfast Diet u Optisource®).

Una vez finalizado este período, los pacientes intervenidos con técnicas de derivación gastrointestinal pasarán a la tercera fase y podrán comer casi con normalidad. Se hará especial hincapié en asegurar un aporte proteico suficiente (más de 60 g/día en el BG y de 90 g/día en la DBP) y en la necesidad de evitar dulces, bebidas hipercalóricas, bebidas carbónicas y alimentos grasos, así como evitar tomar líquidos durante las comidas, para prevenir problemas de tolerancia digestiva (tabla 15).

TABLA 15. Recomendaciones nutricionales después

Objetivos

Facilitar la tolerancia digestiva, prevenir el síndrome de vaciamiento rápido, la esteatorrea y la malnutrición

Conseguir la mayor reducción posible de la grasa corporal excedente y, posteriormente, el mejor mantenimiento del nuevo peso corporal

Reeducación nutricional: alimentación hipocalórica adaptada a los cambios anatómicos y funcionales inducidos por la cirugía

Recomendaciones generales

Hacer comidas frecuentes y poco voluminosas, repartidas en 6 tomas/día (desayuno, media mañana, comida, merienda, cena, antes de dormir)

Comer despacio y masticar mucho los alimentos (20-30 veces.

Cada comida debe durar al menos 30 min. Dejar de comer cuando se tenga sensación de saciedad o "nudo"

Aporte adecuado de proteínas (pescados, carnes, huevos, lácteos): al menos 60 g/día

Priorizar la ingesta de alimentos proteicos (tomarlos en primer lugar en cada comida)

Restringir azúcares simples. Evitar bebidas azucaradas y altamente osmóticas

Reducir el consumo de grasas. Utilizar pescado y carnes blancas, lácteos desnatados. Cocinar de forma sencilla, evitando fritos, guisos, rebozados y salsas

El consumo de fibra (frutas, vegetales, preparados de fibra soluble) puede ser útil para retrasar el vaciamiento gástrico y enlentecer el tránsito digestivo

Las verduras deben tomarse preferentemente cocinadas. Evitar verduras flatulentas (coliflor, repollo, coles de Bruselas, etc.)

No beber durante las comidas, hacerlo 30-60 min antes o después. Ingerir 1-1,5 1 de agua-líquidos/día, fuera de las comidas (100 ml cada vez)

Evitar cítricos (1 mes), alcohol, bebidas carbónicas y alimentos muy fríos o muy calientes

$\mathrm{Si}$ hay intolerancia a la lactosa, utilizar leche sin lactosa, limitar el consumo de lácteos y/o fraccionar en tomas pequeñas (50-100

$\mathrm{ml}$ ). El yogur suele tolerarse mejor que otros derivados

Pueden consumirse pequeñas cantidades de alimentos azucarados en pacientes con cruce duodenal (al estar preservado el píloro no suele aparecer síndrome de dumping)

Recordar:

Suplementos multivitamínicos-minerales, calcio, vitamina D y hierro (en mujeres con menstruaciones) para prevenir deficiencias de micronutrientes

Tomar los medicamentos triturados o en forma líquida

En caso de vómitos súbitos repetidos o diarrea, contactar con el equipo médico responsable 
La ingesta de alcohol está especialmente contraindicada, ya que los pacientes con exclusión o resección gástrica presentan, por diferentes mecanismos, un aumento de la toxicidad inducida por etanol.

En todos los casos, se deben evitar la aspirina, el resto de antiinflamatorios no esteroideos y los bisfosfonatos por su potencial ulcerógeno. Se recomienda la administración de protectores gástricos (anti$\mathrm{H}_{2}$ o inhibidores de la bomba de protones) durante el primer año postoperatorio. (Grado de recomendación $D$ )

Es importante vigilar y ajustar el tratamiento médico de las comorbilidades preoperatorias como la DM o la hipertensión, ya que tras la intervención habrá una disminución importante de los requerimientos $\mathrm{y}$, en muchos casos, incluso no será necesario el tratamiento farmacológico ${ }^{33-35}$. (Grado de recomendación $B$ )

\section{Suplementos de micronutrientes}

Todos los pacientes requieren suplemento rutinario de vitaminas y minerales para prevenir deficiencias de micronutrientes ${ }^{113,136}$. (Grado de recomendación A)

Después de la intervención, deben administrarse suplementos de hierro durante 2 meses (manteniéndose en mujeres con menstruaciones), preparados de multivitaminas/minerales (dosis variable, según la técnica quirúrgica) y suplementos de calcio (más vitamina $\mathrm{D}_{3}$ ) con las técnicas mixtas, de forma indefinida.

En España no hay ningún preparado multivitamínico dirigido específicamente a este tipo de pacientes. En la tabla 16 se muestran las diferencias en la composición de los preparados más utilizados. 
TABLA 16. Contenido en los principales micronutrientes de algunos preparados comerciales multivitamínicos de uso frecuente

\begin{tabular}{|c|c|c|c|c|c|c|c|c|c|c|c|c|c|c|c|c|c|c|}
\hline & $\begin{array}{l}\text { Vitamina } \\
\mathrm{B}_{1}(\mathrm{mg})\end{array}$ & $\begin{array}{l}\text { Vitamina } \\
\mathrm{B}_{2}(\mathrm{mg})\end{array}$ & $\begin{array}{l}\text { Vitamina } \\
\mathrm{B}_{6}(\mathrm{mg})\end{array}$ & $\begin{array}{l}\text { Vitamina } \\
\mathrm{B}_{12}(\mu \mathrm{g})\end{array}$ & $\begin{array}{c}\text { Ácido } \\
\text { fólico } \\
(\mu \mathrm{g})\end{array}$ & $\begin{array}{l}\text { Vitamina } \\
\text { C (mg) }\end{array}$ & $\begin{array}{c}\text { Vitamina } \\
\text { A (U) } \\
3,33 \\
\mathrm{U}=1 \mu \mathrm{g}\end{array}$ & $\begin{array}{l}\text { Vitamina } \\
\mathrm{D}_{2}(\mathrm{U})\end{array}$ & $\begin{array}{c}\text { Vitamina } \\
\mathrm{D}_{3}(\mathrm{U}) \\
40 \\
\mathrm{U}=1 \mu \mathrm{g}\end{array}$ & $\begin{array}{c}\text { Vitamina } \\
\mathrm{E}(\mathrm{U}) \\
1,49 \\
\mathrm{U}=1 \\
\mathrm{mg}\end{array}$ & $\begin{array}{l}\text { Vitamina } \\
\mathrm{K}(\mu \mathrm{g})\end{array}$ & $\begin{array}{c}\text { Hierro } \\
(\mathrm{mg})\end{array}$ & $\begin{array}{c}\text { Calcio } \\
(\mathrm{mg})\end{array}$ & $\begin{array}{l}\text { Magnesio } \\
(\mathrm{mg})\end{array}$ & $\begin{array}{l}\text { Cinc } \\
(\mathrm{mg})\end{array}$ & $\begin{array}{l}\text { Yodo } \\
(\mathrm{mg})\end{array}$ & $\begin{array}{l}\text { Cobre } \\
(\mathrm{mg})\end{array}$ & $\begin{array}{c}\text { Selenio } \\
(\mathrm{mg})\end{array}$ \\
\hline $\begin{array}{l}\text { Multicentrum } \\
\text { Select } 50+\circledR\end{array}$ & 2,1 & 2,4 & 3 & 3 & 300 & 120 & 2.664 & - & 200 & 17,9 & 30 & 3,5 & 162 & 100 & 5 & 100 & 1 & 25 \\
\hline $\begin{array}{l}\text { Multicentrum } \\
\text { Junior }\end{array}$ & $0^{\prime} 5$ & $0^{\prime} 5$ & $0^{\prime} 5$ & 1 & 200 & 50 & 1.099 & - & 120 & 7,45 & 10 & 4,5 & 14,3 & 40 & 2,8 & - & 0,4 & 12,5 \\
\hline $\begin{array}{l}\text { Supradyn } \\
\text { activo® }\end{array}$ & 1,4 & 1,6 & 2 & 1 & 200 & 60 & $\begin{array}{c}2.264 \\
\text { más } \\
720 \mathrm{mg} \\
\text { de beta- } \\
\text { carotenos }\end{array}$ & - & 200 & 14,9 & 30 & 8 & 120 & 45 & 8 & 75 & 0,9 & 55 \\
\hline $\begin{array}{l}\text { Dayamineral } \\
\text { gotas }{ }^{\circledR} 1 \mathrm{ml}(40 \\
\text { gotas) }\end{array}$ & 2,5 & 2 & 0,83 & - & - & 83,3 & 5.000 & 1.667 & - & - & - & 3,3 & - & - & 1,75 & - & - & - \\
\hline $\begin{array}{l}\text { Dayamineral } \\
\text { comprimidos® }\end{array}$ & 10 & 10 & 1,5 & 5 & 250 & 150 & 2.500 & 1.000 & - & - & - & 6,8 & 100 & 40 & 3,9 & 100 & 2,8 & - \\
\hline $\begin{array}{l}\text { Hidropolivit } \\
\text { mineral }{ }^{\circledR}\end{array}$ & 2 & 1 & 1 & 2 & 100 & 40 & 2.500 & - & 500 & 1,49 & 100 & 2 & 1,4 & 6,88 & 0,3 & 10 & 0,4 & - \\
\hline Rochevit ${ }^{\circledR}$ & 1,6 & 1,8 & 2,6 & 4 & 400 & 100 & 2.500 & 400 & - & 22,3 & - & 50 & 150 & 60 & 1,5 & - & 2,8 & - \\
\hline $\begin{array}{l}\text { Micebrina } \\
\text { complex® }\end{array}$ & 10 & 5 & 6 & 12 & 400 & 150 & 1.500 & - & 400 & 30 & - & 18 & 45 & 100 & 15 & 150 & 2 & - \\
\hline
\end{tabular}


En algunos casos serán necesarios, además, otros suplementos específicos posteriormente, según la evolución clínica (tabla 17).

TABLA 17. Suplemento y tratamiento con micronutrientes

Suplemento sistemático

Complejo de multivitaminas-minerales

Técnicas restrictivas: 1 comprimido/día, con las comidas.

Bypass gástrico proximal: 2 comprimidos/día, con las comidas

Derivación biliopancreática, bypass gástrico distal: 3 comprimidos/día, con las comidas

Hierro (a partir del primer mes en las mujeres con menstruaciones y en los pacientes de riesgo por pérdidas crónicas de sangre)

Oral: $40-80 \mathrm{mg}$ /día de hierro elemento (200-400 mg de sulfato ferroso). Controlar los marcadores bioquímicos y hematológicos del mineral (sideremia, ferritina, capacidad de fijación del hierro y hemograma) para ajustar la dosis

Combinación de calcio y vitamina D (en las técnicas mixtas)

Oral: $1.000-1.200 \mathrm{mg} /$ día de calcio elemento (más 800 U/día de vitamina $\mathrm{D}_{3}$ ). Monitorizar las concentraciones de calcio, $25 \mathrm{OH}-\mathrm{D}_{3}$ y PTHi en sangre y de calcio en orina para ajustar la dosis

Tratamiento de las deficiencias específicas

Hierro

Oral: 100-200 mg/día de hierro elemento (500-1.000 mg de sulfato ferroso) en 1 o 2 tomas, fuera de las comidas, con vitamina $\mathrm{C}$

Intravenoso: hierro-sacarosa. Dosis de ataque100 mg 2 veces por semana hasta dosis calculada. Dosis de mantenimiento variable (100-200 mg/1-2 meses)

Vitamina $\mathrm{B}_{12}$

Oral: al menos $350 \mathrm{~g} /$ día en 1 toma.

Intramuscular: dosis de ataque $1.000 \mu \mathrm{g}$ a días alternos durante 7-14 días. Dosis de mantenimiento $1.000 \mathrm{~g} / \mathrm{mes}$

Sales de calcio (más vitamina $\mathrm{D}_{3}$ )

Oral: $1.000-2.000 \mathrm{mg} /$ día de calcio elemento (más 800-1.200 U/día de vitamina $\mathrm{D}_{3}$ ) en 2 o 3 tomas, con las comidas

$25 \mathrm{OH}-\mathrm{D}_{3}$

Oral: dosis de ataque $180.000 \mathrm{U}(3 \mathrm{mg}) / 2-4$ semanas. Dosis de mantenimiento variable (16.00032.000 U/1-2 semanas). Monitorizar las concentraciones de calcio, 25OH-D y PTHi en sangre y de calcio en orina para ajustar la dosis

Sales de magnesio

Oral: $20 \mathrm{mmol} / \mathrm{día}$ de magnesio elemento en 2-3 tomas, con las comidas

Ácido fólico

Oral: $10-20 \mathrm{mg} /$ día en 2 tomas, antes de las comidas

Vitamina $\mathrm{B}_{1}$ (tiamina)

Intramuscular o intravenosa lenta (dosis de ataque): $100 \mathrm{mg}$ /día durante 7-14 días

Oral (posteriormente): $10 \mathrm{mg} /$ día hasta la máxima recuperación neurológica

Vitamina A

Oral: dosis de ataque 50.000 U/día durante 1-2 semanas.

Posteriormente 50.000 U 2 veces/semana hasta la normalización de las concentraciones plasmáticas de la vitamina

Cinc

Oral: 40-100 mg/día de cinc elemento (176-440 mg de sulfato de cinc) en 1 o 2 tomas, con las comidas

25OH-D ${ }_{3}$ : calcifediol; PTHi: hormona paratiroidea intacta. 
Se recomienda prescribir preparados preferentemente líquidos $\mathrm{y}$, si no es posible, comprimidos o cápsulas de pequeño tamaño.

\section{Período postoperatorio temprano (fig. 3)}

Durante esta etapa tiene lugar una pérdida acelerada de peso, y pueden aparecer problemas de tolerancia digestiva secundarios generalmente a dificultades de adaptación a la dieta postoperatoria (aprendizaje de nuevos hábitos alimentarios) y ocasionalmente a complicaciones de la técnica quirúrgica (estenosis del estoma o de la anastomosis, úlceras marginales, rotura de las grapas y otros) ${ }^{137}$. El riesgo de deficiencias nutricionales aumenta, en la mayoría de los casos, a partir del primer año de la intervención ${ }^{133}$.

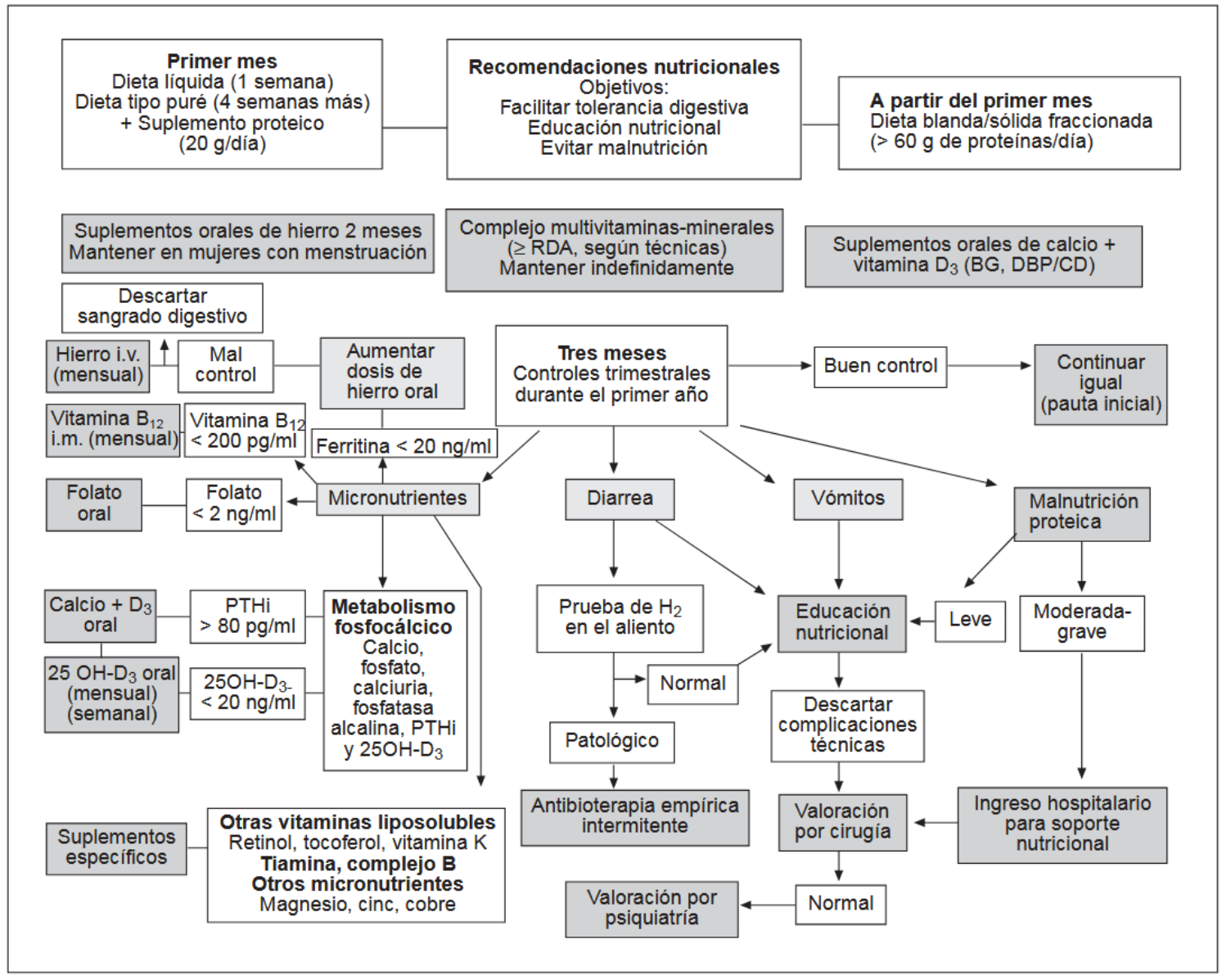

Fig. 3. Cirugía bariátrica. Algoritmo de seguimiento postoperatorio. BG: bypass gástrico; CD: cruce duodenal; DBP: derivación biliopancreática; PTHi: hormona paratiroidea intacta; RDA: Recommended Dietary Allowances 
Vómitos

Ocurren casi siempre entre las primeras semanas y los primeros meses del postoperatorio, por sobrealimentación o por no masticar adecuadamente la comida. Suelen ser ocasionales, y mejoran con educación nutricional. Si se hacen frecuentes, pueden producir deshidratación, hipopotasemia y/o hipomagnesemia, por lo que es necesario rehidratación y suplementación intravenosa. Una de las consecuencias nutricionales más graves de los vómitos persistentes con intolerancia alimentaria es la deficiencia de tiamina, que si no se reconoce y trata a tiempo puede causar daños irreversibles en el sistema nervioso central o insuficiencia cardíaca y muerte súbita ${ }^{36}$. En pacientes de riesgo, se recomienda la administración profiláctica de suplementos de tiamina. (Grado de recomendación $C$ )

Tras las cirugías restrictivas (BGAL, GVB), en las etapas iniciales, los vómitos repetidos pueden asociarse a inflamación y edema del rodete gástrico. Si no responden a omeprazol a dosis altas (40 $\mathrm{mg}$ /día) y dieta líquida estricta, puede intentarse un tratamiento de prueba con metilprednisolona (250 $\mathrm{mg}$ /día por vía intramuscular durante $48 \mathrm{~h}$ ) antes de descartar complicaciones técnicas.

La persistencia de vómitos meses después de la intervención, especialmente si se acompañan de disfagia o hay repercusión nutricional, suele indicar la existencia de un problema orgánico. En caso de intolerancia a sólidos, debe sospecharse estenosis del estoma o de la anastomosis y realizar una evaluación endoscópica ${ }^{137}$. Si se confirmase, puede tratarse en el momento del diagnóstico mediante dilatación con balón ${ }^{138}$. La mayoría de estos pacientes requerirán dilataciones repetidas, hasta que sean capaces de tolerar comidas sólidas.

\section{Síndrome de dumping}

Ocurre con una frecuencia variable (de un 10 a un 50\% de los casos) después del BG y de las técnicas de DBP, excepto el CD, al mantener el píloro en el trayecto alimentario ${ }^{91}$. La llegada directa de alimentos hiperosmolares no digeridos (bebidas azucaradas, helados, pasteles, etc.) al intestino delgado, como resultado del rápido vaciamiento del reservorio gástrico, produce entrada de líquido en la luz intestinal, hipovolemia relativa, reacción vagal e hiperinsulinismo, y ocasiona un cortejo sintomático caracterizado por inestabilidad, rubefacción facial, hipersudoración, debilidad intensa, taquicardia, dolor abdominal, náuseas, vómitos y, ocasionalmente, diarrea, que aparece entre 30 y 90 min después de la ingesta. A pesar de lo alarmante de los síntomas, no suele haber repercusión nutricional, ya que el intestino distal es suficiente para absorber los alimentos en la mayoría de los casos. Este efecto podría favorecer la anorexia postoperatoria y la aversión por los dulces que presentan muchos de los pacientes sometidos a BG, y ser la causa, al menos en parte, de los mejores resultados con respecto a las técnicas restrictivas ${ }^{62}$. (Grado de recomendación $B$ )

El tratamiento consiste en modificaciones dietéticas: restringir azúcares simples, disminuir el volumen de las tomas y evitar tomar líquidos durante las comidas. Puede ser útil la adición de fibra soluble para retrasar el vaciamiento gástrico y enlentecer el tránsito intestinal.

\section{Deshidratación}

Debido al pequeño tamaño del reservorio gástrico y a la necesidad de tomar los líquidos fuera de las comidas, es prioritario enseñar a los pacientes a beber con frecuencia agua o líquidos acalóricos a pequeños tragos para satisfacer sus requerimientos hídricos. (Grado de recomendación D)

Los casos leves de deshidratación suelen responder bien a bebidas deportivas de reposición diluidas al $50 \%{ }^{133}$. Si no mejorasen, es necesaria la hospitalización. 


\section{Cálculos biliares}

$\mathrm{Su}$ formación es frecuente en este período, debido a la pérdida rápida de peso y pueden ser sintomáticos $(40 \%)^{139}$. Debe realizarse siempre una ecografía preoperatoria y, en caso necesario, practicar una colecistectomía ${ }^{38}$. Algunos autores recomiendan que los pacientes no colecistectomizados reciban tratamiento profiláctico con un agente solubilizador (ácido ursodeoxicólico) durante al menos 6 meses ${ }^{140}$. (Grado de recomendación B)

\section{Deficiencias nutricionales}

Aunque el riesgo aumente a partir del primer año, pueden aparecer tempranamente en caso de vómitos repetidos por complicaciones técnicas (estenosis del estoma o de la anastomosis gastroyeyunal), y más raramente en pacientes con ingesta excesivamente restrictiva o un trastorno previo (inadvertido) del comportamiento alimentario.

La deficiencia de tiamina $\left(\mathrm{B}_{1}\right)$ y otras vitaminas del grupo $\mathrm{B}$ pueden ocasionar cuadros clínicos graves, destacando las alteraciones neurológicas agudas y especialmente la encefalopatía de Wernicke. En pacientes de riesgo se recomienda la administración profiláctica de suplementos de tiamina. (Grado de recomendación $C$ )

Ante vómitos recurrentes, se administrará tiamina por vía parenteral (100 mg/día durante 7-14 días, según evolución) y posteriormente oral (10 mg/día, hasta la recuperación completa). (Grado de recomendación $B$ )

Si se desarrolla malnutrición proteica, las fórmulas hiperproteicas bajas en hidratos de carbono (VEGEfast ${ }^{\circledR}$ Complet, Optisource $\left.{ }^{\circledR}\right)$ o los suplementos proteicos disponibles para administración oral suelen ser efectivos en grados leves. En caso de intolerancia o ausencia de respuesta, es necesario hospitalizar al paciente para soporte nutricional, generalmente parenteral.

La pérdida de cabello es frecuente durante los primeros meses poscirugía, debido a la pérdida acelerada de peso y la interrupción del ciclo de crecimiento normal del cabello. Aunque sea alarmante para el paciente, suele recuperarse sin tratamiento.

\section{Período postoperatorio tardío}

Después del primer año postoperatorio, y una vez estabilizado el peso corporal, es necesario mantener el seguimiento a largo plazo para poder detectar y tratar a tiempo complicaciones tardías, vigilando especialmente la posible aparición de deficiencias nutricionales.

Además de los riesgos nutricionales intrínsecos de la técnica quirúrgica (mayores con los procedimientos malabsortivos), el cumplimiento del tratamiento por el paciente y la calidad de la alimentación condicionan, en la práctica, la aparición de complicaciones nutricionales ${ }^{136}$. Es importante insistir en el mantenimiento de unos buenos hábitos alimentarios, introducir modificaciones dietéticas en caso de intolerancia a algún componente de la dieta, detectar tempranamente las deficiencias $\mathrm{y}$, consecuentemente, administrar los suplementos adecuados para evitar secuelas clínicas.

\section{Deficiencia de hierro (ferropenia y anemia ferropénica)}

Es muy frecuente en mujeres con menstruaciones (hasta un 50\%), y puede aparecer en los primeros meses, e incluso años, después de la intervención ${ }^{113,141}$, por lo que es necesario controlar el hemograma y los valores de ferritina, el marcador más sensible de las reservas de hierro, en cada revisión. La administración profiláctica de sulfato ferroso oral $(525 \mathrm{mg} /$ día inicialmente, fuera de las comidas, junto con vitamina $\mathrm{C}$ para facilitar su absorción) suele ser efectiva ${ }^{142}$ y debe indicarse en todas las mujeres con menstruaciones. (Grado de recomendación A) 
En caso de ferropenia (ferritina $<20 \mu \mathrm{g} / \mathrm{l}$ ) a pesar de dosis altas o si hay intolerancia a los preparados orales, se administrará tratamiento parenteral con hierro sacarosa en infusión intravenosa (inicialmente $100 \mathrm{mg} / 2$ veces por semana hasta reponer el déficit de hierro). Para calcular la dosis necesaria se puede utilizar la fórmula: déficit total de hierro $(\mathrm{mg})=$ peso $(\mathrm{kg})$ (hemoglobina deseada - hemoglobina actual $[\mathrm{g} / \mathrm{l}]) \times 0,24+500 \mathrm{mg}$. Una vez alcanzada la dosis calculada, se programarán infusiones periódicas, varias veces al año. La administración puede realizarse de forma ambulatoria en el hospital de día.

La ferropenia persistente exige descartar hemorragia digestiva. Las úlceras marginales de la anastomosis gastroyeyunal pueden causar frecuentemente pérdidas hemáticas y dolor abdominal ${ }^{137}$. Se recomienda la administración profiláctica de protectores gástricos durante el primer año postoperatorio. (Grado de recomendación D)

\section{Deficiencia de vitamina $B_{12}$}

$\mathrm{Su}$ incidencia aumenta progresivamente a partir del primer año de la intervención, por lo que puede ser muy frecuente a largo plazo $(26-70 \%)$, si no se suplementa ${ }^{143}$. Deben controlarse los valores plasmáticos en cada revisión e iniciar el tratamiento tras verificar su disminución $(<200 \mathrm{pg} / \mathrm{ml})$. (Grado de recomendación $C$ )

En nuestro medio, hay preparados de vitamina $\mathrm{B}_{12}$ para administración oral y parenteral. Aunque la pauta óptima no esté bien establecida, dosis orales de al menos $350 \mu \mathrm{g} /$ día pueden ser suficientes para mantener valores plasmáticos normales ${ }^{144}$. Si los pacientes no responden al tratamiento oral, se indicarán inyecciones intramusculares mensuales de $1.000 \mu \mathrm{g}$.

\section{Deficiencia de calcio y vitamina $D$}

Los pacientes intervenidos con técnicas preferentemente malabsortivas presentan un riesgo muy elevado (superior al 60\%) de complicaciones óseas (disminución de masa ósea y problemas de mineralización/osteomalacia), asociadas a disminución de la ingesta y malabsorción de calcio y vitamina $\mathrm{D}$ con hiperparatiroidismo secundario ${ }^{145}$. Son más prevalentes en pacientes con un canal común más corto $(\text { menos de } 100 \mathrm{~cm})^{146}$. Varios estudios recientes han demostrado también este problema en pacientes con $\mathrm{BG}^{147-150}$, en los que la frecuencia a largo plazo es superior a la estimada previamente, sobre todo en mujeres posmenopáusicas ${ }^{151}$, así como en pacientes obesos antes de la cirugía ${ }^{152,153}$.

Actualmente se recomienda el control periódico del metabolismo óseo y la administración profiláctica de calcio y vitamina $\mathrm{D}$ en todos los casos de CB mixta. (Grados de recomendación A y D)

Durante el seguimiento, se deben controlar, junto con los valores séricos de calcio, fosfato y fosfatasa alcalina, las concentraciones de $25 \mathrm{OH}-\mathrm{D}_{3}$ (calcifediol) y de hormona paratiroidea intacta (PTHi). Además se aconseja la medida de la densidad mineral ósea, pero no hay guías específicas para el tratamiento en este tipo de pacientes.

Como profilaxis, se utilizarán sales de calcio que aporten 1.200-2.000 mg/día de calcio elemento (más vitamina $\mathrm{D}_{3}$ ), según la técnica utilizada, el sexo y la edad del paciente. El citrato cálcico es la sal idónea, pero hasta hace pocos meses no había preparados comercializados en España, por lo que solía utilizarse inicialmente carbonato cálcico, recurriendo a otras sales (pidolato, fosfato) en caso de intolerancia. Si persiste elevación de PTHi y/o disminución de los valores de $25 \mathrm{OH}-\mathrm{D}_{3}$, a pesar de los suplementos profilácticos, debe asociarse tratamiento oral con dosis elevadas de vitamina D (colecalciferol, calcifediol). La mayoría de pacientes responden al tratamiento, normalizando los valores de PTHi. En casos resistentes, se solicitará tratamiento con vitamina $\mathrm{D}_{3}$ para uso parenteral (vitamine $\mathrm{D}_{3}$ B.O.N. ampollas $200.000 \mathrm{U} / \mathrm{ml})$. 


\section{Otras deficiencias de micronutrientes}

Además de administrar profilácticamente suplementos de tiamina en pacientes de riesgo, es conveniente vigilar los valores séricos de ácido fólico, magnesio y cinc, aunque los complejos multivitamínicos-minerales suelen ser suficientes para evitar su deficiencia. En las técnicas malabsortivas deben controlarse otras vitaminas liposolubles, como retinol (vitamina A) y tocoferol (vitamina E), así como la actividad de protrombina (marcador de la deficiencia de vitamina K), especialmente en caso de diarrea. (Grado de recomendación C)

La deficiencia subclínica de vitamina A podría estar presente en más del $60 \%$ de pacientes sometidos a DBP a largo plazo ${ }^{154}$, pero las complicaciones oftalmológicas parecen poco frecuentes (3\% de ceguera nocturna en la serie de Scopinaro et $\mathrm{al}^{73}$ ). El tratamiento sustitutivo revierte los síntomas. Marceau et $\mathrm{al}^{74}$ recomiendan la administración de $25.000 \mathrm{U} /$ día, pero es necesario realizar el seguimiento de las concentraciones plasmáticas por el riesgo de hepatotoxicidad.

La deficiencia de vitamina E es rara y hasta el momento no se ha demostrado que tenga repercusión clínica $^{154}$.

\section{Malnutrición proteica}

Es una complicación potencialmente grave, pero poco frecuente actualmente, asociada en la mayoría de los casos a las técnicas de predominio malabsortivo (muy rara en el BG proximal) ${ }^{147}$. Suele ser secundaria a complicaciones relacionadas con la técnica quirúrgica o a la falta de cumplimiento de las recomendaciones médicas y nutricionales. Su prevalencia oscila entre el 0 y el $30 \%$, según las series, dependiendo del tamaño del reservorio gástrico (más riesgo si se deja una cavidad gástrica muy reducida, como ocurre en el $\mathrm{BG}$ distal ${ }^{90}$, del diámetro del neoestoma gastroyeyunal, longitudes del canal alimentario (menor de $200 \mathrm{~cm})^{73}$ y del canal común (menor de $\left.100 \mathrm{~cm}\right)^{155,156}$ y de la presencia de sobrecrecimiento bacteriano. (Grados de recomendación $B$ y $C$ ).

Clínicamente, se caracteriza por hipoalbuminemia, anemia, edema, astenia y alopecia. Se debería vigilar el desarrollo de malnutrición proteica ante cualquier circunstancia que aumente los requerimientos o produzca una mala utilización de las proteínas (infección, cirugía, ciertos tratamientos como glucocorticoides o quimioterápicos, embarazo, etc. $)^{135}$, por lo que hay que controlar los valores séricos de albúmina y transferrina para iniciar de modo temprano el tratamiento y evitar secuelas clínicas. En casos leves, pueden ser suficientes las modificaciones dietéticas y la administración de una fórmula hiperproteica o un suplemento proteico por vía oral. Los casos graves requieren hospitalización para soporte nutricional parenteral, y casi siempre precisan de cirugía de reconversión bariátrica.

\section{Diarrea}

Puede estar relacionada con la ingesta excesiva de grasas, esteatorrea, intolerancia a la lactosa y sobrecrecimiento bacteriano. En caso de diarrea persistente con hipoalbuminemia y/o pérdida de peso, se debe descartar la presencia de sobrecrecimiento bacteriano y realizar, si es posible, cultivo de las secreciones intestinales o una prueba de $\mathrm{H}_{2}$ en el aliento con lactulosa ${ }^{157}$, o bien administrar antibióticos empíricamente ante la sospecha clínica. Puede utilizarse una pauta de tratamiento oral intermitente (una semana al mes durante 4-6 meses). (Grado de recomendación $D$ )

Si el resultado es negativo y hay esteatorrea, los síntomas suelen mejorar con la administración de dietas pobres en grasa enriquecidas con triglicéridos de cadena media. Algunos autores recomiendan enzimas pancreáticas. En casos más graves, puede ser necesario recurrir a nutrición parenteral. 


\section{Gestación tras cirugía bariátrica}

Una pérdida de peso superior al $15 \%$ puede normalizar algunos estados hiperandrogénicos secundarios a la obesidad, y mejorar las irregularidades menstruales y la fertilidad ${ }^{158,159}$. Por ello, y teniendo en cuenta que el principal segmento de edad en pacientes sometidos a CB lo constituyen mujeres menores de 35 años, no es infrecuente observar una tasa elevada de embarazos.

Hay numerosas evidencias de que una gestación en una mujer sometida a $\mathrm{CB}$, con un peso estable y un estado nutricional optimizado, no presenta ninguna diferencia estadística en cuanto a complicaciones durante la gestación, ni un índice de diabetes gestacional mayor ${ }^{160}$, respecto a pacientes con normopeso de la misma edad, tanto con técnicas restrictivas como mixtas ${ }^{161-165}$, con la única excepción de un índice mayor de hernias abdominales en cirugías abiertas ${ }^{166}$ y de una necesidad de ajuste de la banda durante el embarazo $^{161,167}$. (Grados de recomendación B y C)

Por otra parte, cabe destacar que mujeres obesas que se han tratado mediante CB tengan menos complicaciones relacionadas con la gestación (diabetes gestacional, problemas osteoarticulares, insuficiencia venosa, preeclamsia, macrosomía) que las mujeres obesas no intervenidas ${ }^{161-163}$.

Sin embargo, debemos recomendar a las pacientes de edad fértil retrasar el embarazo hasta 1-2 años después de la intervención, evitar el embarazo en períodos de pérdida rápida de peso y asegurar un estado nutricional óptimo, especialmente en las pacientes con antecedentes de cirugía derivativa.

Además de suplementos con ácido fólico y yodo, debemos tener presentes los suplementos de hierro, vitamina $\mathrm{B}_{12}$, calcio y proteínas (de especial interés de cara a la lactancia), incluso a dosis mayores de las habituales debido al mayor volumen de distribución de estas pacientes. Es importante no administrar dosis elevadas de vitamina A y $25 \mathrm{OH}-\mathrm{D}_{3}$ (calcifediol) por su potencial efecto teratógeno. Asimismo, se recomienda realizar un control analítico exhaustivo en cada trimestre de la gestación ${ }^{168}$.

Por otra parte, en las pacientes embarazadas con antecedentes de CB, se deben evitar los test de sobrecarga oral con glucosa para el cribado y el diagnóstico de diabetes gestacional por la alteración existente en el patrón de vaciamiento gástrico y de la absorción intestinal de glucosa, así como por el desacoplamiento entre las tasas de absorción intestinal y las del aclaramiento plasmático de glucosa, que pueden determinar hipoglucemias reactivas muy intensas tras la sobrecarga oral con glucosa.

\section{CONCLUSIONES}

A pesar de los avances en el tratamiento farmacológico de la obesidad, el tratamiento quirúrgico continuará siendo la principal opción terapéutica para los pacientes con OM, al menos en los próximos años. La indicación del tratamiento quirúrgico requiere la intervención de un equipo hospitalario multidisciplinario e implica un compromiso a lo largo de la vida, tanto para el paciente como para el equipo médico responsable de su seguimiento. Son imprescindibles una valoración preoperatoria cuidadosa y un seguimiento postoperatorio atento para minimizar los efectos adversos de la intervención. Una vez estabilizado el peso corporal, se recomienda programar revisiones anuales en el centro donde se practicó la intervención, para poder actualizar y analizar los resultados a largo plazo. 


\section{BIBLIOGRAFÍA}

1. WHO consultation on obesity. Obesity: preventing and managing the global epidemic. Ginebra. World Health Organization, June 3-5, 1997. (WHO technical report series n. ${ }^{\circ} 894$ ).

2. American Society for Bariatric Surgery, Standards Committee. Guidelines for reporting results in bariatric surgery. Obes Surg, 7 (1997), pp. 521-522

3. Sociedad Española para el Estudio de la Obesidad (SEEDO). Consenso SEEDO'2000 para la evaluación del sobrepeso y la obesidad y el establecimiento de criterios de intervención terapéutica. Med Clin (Barc), 115 (2000), pp. 587-597

4. J. Salas-Salvadó, M.A. Rubio, M. Barbany, B. Moreno, Grupo colaborativo de la SEEDO. Consenso SEEDO 2007 para la evaluación del sobrepeso y la obesidad y el establecimiento de criterios de intervención terapéutica. Med Clin (Barc), 128 (2007), pp. 184-196

5. NHLBI Obesity Task Force. Clinical guidelines on the identification, evaluation, and treatment of overweight and obesity in adults-the evidence report. Obes Res, 6 (Suppl 2) (1998), pp. 51S$209 \mathrm{~S}$

6. K.G.M.M. Alberti, P. Zimmet, J. Shaw, For the IDF Epidemiology Task Force Consensus Group. The metabolic syndrome. A new worldwide definition. Lancet, 366 (2005), pp. 10591062

7. M. Deitel. Overweight and obesity worldwide now estimated to involve 1,7 billon people. Obes Surg, 13 (2003), pp. 329-330

8. A.H. Mokdad, B.A. Bowman, E.S. Ford, F. Vinicor, J.S. Marks, J.P. Koplan. The continuing epidemics of obesity and diabetes in the United States. JAMA, 286 (2001), pp. 1195-1200

9. J. Aranceta-Bartrina, L. Serra-Majem, M. Foz-Sala, B. Moreno-Esteban, Grupo colaborativo SEEDO. Prevalencia de obesidad en España. Med Clin (Barc), 125 (2005), pp. 460-466

10. J. Aranceta, C. Pérez Rodrigo, L. Serra Majem, L. Ribas Barba, J. Quiles Izquierdo, J. Vioque, et al. Prevalencia de obesidad en España: resultados del estudio SEEDO 2000. Med Clin (Barc), 120 (2003), pp. 608-612

11. L. Serra-Majem, L. Ribas Barba, J. Aranceta Bartrina, C. Pérez Rodrigo, P. Saavedra Santana. Epidemiologia de la obesidad infantil y juvenil en España. Resultados del estudio enKid (19982000). En: L. Serra-Majem, J. Aranceta Bartrina (Eds.), Obesidad infantil y juvenil: estudio enKid, Masson, Barcelona (2001), pp. 81-108

12. J. Aranceta, C. Perez Rodrigo, M. Foz Sala, T. Mantilla, L. Serra Majem, B. Moreno, et al. Estudio Dorica. Med Clin (Barc), 123 (2004), pp. 686-691

13. C.L. Ogden, M.D. Carroll, L.R. Curtin, M.A. McDowell, C.J. Tabak, K.M. Flegal. Prevalence of overweight and obesity in the United States, 1999-2004. JAMA, 295 (2006), pp. 1549-1555

14. F.X. Pi-Sunyer. A review of long-term studies evaluating the efficacy of weight loss in ameliorating disorders associated with obesity. Clin Ther, 18 (1996), pp. 1006-1035

15. E.E. Calle, M.J. Thun, J.M. Petrelli, C. Rodríguez, C.W. Heath Jr. Body mass index and mortality in a prospective cohort of U. S. adults. N Engl J Med, 341 (1999), pp. 1097-1105

16. E.B. Rimm, M.J. Stampfer, E. Giovannucci, A. Ascherio, D. Spiegelman, G.A. Colditz, et al Body size and fat distribution as predictors of coronary heart disease among middle aged and older US men. Am J Epidemiol, 141 (1995), pp. 1117-1127

17. C.D. Brown, M. Higgins, K.A. Donato, F.C. Rohde, R. Garrison, E. Obarzanek, et al. Body mass index and the prevalence of hypertension and dyslipidemia. Obes Res, 8 (2000), pp. 605619

18. J.M. Chan, E.B. Rimm, G.A. Colditz, M.J. Stampfer, W.C. Willet. Obesity, fat distribution, and weight gain as risk factors for clinical diabetes in men. Diabetes Care, 17 (1994), pp. 961-969

19. V.J. Carey, E.E. Walters, G.A. Colditz, C.G. Solomon, W.C. Willett, B.A. Rosner, et al. Body fat distribution and risk of non-insulin-dependent diabetes mellitus in women. The Nurses' Health Study. Am J Epidemiol, 145 (1997), pp. 614-619

20. Bergstrom, P. Pisani, V. Tenet, A. Wolk, H.O. Adami. Overweight as an avoidable cause of cancer in Europe. Int J Cancer, 91 (2001), pp. 421-430

21. G.A. Bray. Medical consequences of obesity. J Clin Endocrinol Metab, 89 (2004), pp. 2583 2589

22. J.L. Weiss, F.D. Malone, D. Emig, R.H. Ball, D.A. Nyberg, C.H. Comstock, et al. FASTER research consortium. Obesity, obstetric complications and cesarean delivery rate, a populationbased screening study. Am J Obstet Gynecol, 190 (2004), pp. 1091-1097

23. T. Lang, R. Hauser, R. Schlumpf, R. Klaghofer, C. Buddeberg. Psychic comorbidity and quality of life in patients with morbid obesity applying for gastric Banding. J Suis Med, 130 (2000), pp. 739-748 
24. R. Saunders. Binge eating in gastric bypass patients before surgery. Obes Surg, 9 (1999), pp. $72-76$

25. T. Pekkarinen, P. Mustajoki. Comparison of behavior therapy with and without very-lowenergy diet in the treatment of morbid obesity. A 5-year outcome. Arch Intern Med, 157 (1997), pp. 1581-1585

26. L.K. Khan, M.K. Serdul, B.A. Bowman, D.F. Williamson. Use de prescription weight loss pills among U.S adults in 1996-98. Ann Intern Med, 134 (2001), pp. 282-286

27. Z. Li, M. Maglione, W. Tu, W. Mojica, D. Arterburn, L.R. Shugarman, L. Hilton, et al. Metaanalysis: pharmacologic treatment of obesity. Ann Intern Med, 142 (2005), pp. 532-546

28. F.X. Pi-Sunyer, L.J. Aronne, H.M. Heshmati, J. Devin, J. Rosenstock, For the RIO-North America Study Group. Effect of rimonabant, a cannabinoid-1 receptor blocker, on weight and cardiometabolic risk factors in overweight or obese patients: RIO-North America: a randomized controlled trial. JAMA, 295 (2006), pp. 761-775

29. L.F. Van Gaal, A.M. Rissanen, A.J. Scheen, O. Ziegler, S. Rossner, RIO-Europe Study Group. Effects of the cannabinoid-1 receptor blocker rimonabant on weight reduction and cardiovascular risk factors in overweight patients: 1-year experience from the RIO-Europe study. Lancet, 365 (2005), pp. 1389-1397

30. T. Andersen, O.G. Backer, K.H. Stokholm, F. Quaade. Randomized trial of diet and gastroplasty compared with diet alone in morbid obesity. N Engl J Med, 310 (1984), pp. $352-$ 356

31. C.D. Sjostrom, L. Lissner, H. Wedel, L. Sjostrom. Reduction in incidence of diabetes, hypertension and lipid disturbances after intentional weight loss induced by bariatric surgery: the SOS Intervention Study. Obes Res, 7 (1999), pp. 477-484

32. L. Sjostrom, A.K. Lindroos, M. Peltonen, J. Torgerson, C. Bouchard, B. Carlsson, et al. Lifestyle, diabetes and cardiovascular risk factors 10 years after bariatric surgery. N Engl J Med, 351 (2004), pp. 2683-2693

33. J. Colquitt, A. Clegg, E. Loveman, P. Royle, M.K. Sidhu. Surgery for morbid obesity. Cochrane Database Syst Rev, 4 (2005) CD003641

34. H. Buchwald, Y. Avidor, E. Braunwald, M.D. Jensen, W. Pories, K. Fahrbach, et al. Bariatric surgery: a systematic review and meta-analysis. JAMA, 292 (2004), pp. 1724-1737

35. M.A. Maggard, L.R. Shugamman, M. Suttorp, M. Maglione, H.J. Sugerman, E.H. Livingston, et al. Meta-Analysis: surgical treatment of obesity. Ann Intern Med, 142 (2005), pp. 547-559

36. J.J. Arrizabalaga, L. Masmiquel, J. Vidal, A. Calañas-Continente, M.J. Díaz-Fernández, P.P. García-Luna, et al. Recomendaciones y algoritmo de tratamiento del sobrepeso y la obesidad en personas adultas. Med Clin (Barc), 122 (2004), pp. 104-110

37. Consensus Development Conference Panel for Gastrointestinal surgery for severe obesity. Ann Intern Med. 1991;115:956-61.

38. Sociedad Española de Cirugía de la Obesidad. Recomendaciones de la SECO para la práctica de la cirugía bariátrica (Declaración de Salamanca). Cir Esp, 75 (2004), pp. 312-314

39. W.H. Dietz. Health consequences of obesity in youth: childhood predictors of adult disease. Pediatrics, 101 (1998), pp. 518-525

40. C.M. Apovian, C. Baker, D.S. Ludwing, A.G. Hoppin, G. Hsu, C. Lenders, et al. Best Practice Guideline in Pediatric/Adolescent Weight Loss Surgery. Obes Res, 13 (2005), pp. 274-282

41. T.H. Inge, V. Garcia, S. Daniels, L. Langford, S. Kirk, H. Roehrig, et al. A multidisciplinary approach to the adolescent bariatric surgical patient. J Pediatr Surg, 39 (2004), pp. 442-447

42. D.R. Flum, L. Salem, J.A. Elrod, E.P. Dellinger, A. Cheadle, L. Chan. Early mortality among Medicare beneficiaries undergoing bariatric surgical procedures. JAMA, 294 (2005), pp. 1903 1908

43. Lehman center weight loss surgery expert panel. Commonwealth of Massachusetts Betsy Lehman Center for patient safety and medical error reduction. Expert panel on weight loss surgery executive report. Obes Res. 2005;13:205-26.

44. E.H. Livingston, S. Huerta, D. Arthur, S. Lee, S. De Shiuelds, D. Heber. Male gender is a predictor of morbidity and age a predictor of mortality for patients undergoing gastric bypass surgery. Ann Surg, 236 (2002), pp. 576-582

45. M.L. Schwartz, R.L. Drew, M. Chazin-Caldie. Laparoscopic Roux-en Y gastric by-pass: preoperative determinants of prolonged operative times, conversion to open gastric bypasses, and postoperative complications. Obes Surg, 13 (2003), pp. 734-738

46. E. Saltzman, W. Anderson, C.M. Apovian, H. Boulton, A. Chamberlain, D. Cullum-Dugan, et al. Criteria for patient selection and multidisciplinary evaluation and treatment of the weight loss surgery patient. Obes Res, 13 (2005), pp. 234-243 
47. J.A. Guisado, F.J. Vaz, J. Alarcon, J.J. López-Ibor Jr, M.A. Rubio, L. Gaite. Psychopathological status and interpersonal functioning following weight loss in morbidly obese patients undergoing bariatric surgery. Obes Surg, 12 (2002), pp. 835-840

48. C. Delgado Calvete, M.J. Morales Gorría, I. Maruri Chimeno, C. Rodríguez del Toro, J.L. Benavente Martín, S. Núñez Bahamonte. Conducta alimentaria, actitudes hacia el cuerpo y psicopatología en obesidad mórbida. Actas Esp Psiquiatr, 30 (2002), pp. 376-381

49. S. Herpertz, R. Kielmann, A.M. Wolf, J. Hebebrand, W. Senf. Do psychosocial variables predict weight loss or mental health after obesity surgery? A systematic review. Obes Res, 12 (2004), pp. 1554-1569

50. S.L. Colles, J.B. Dixon, P. Marks, B.J. Strauss, P.E. O’Brien. Preoperative weight loss with a very-low-energy diet: quantitation of changes in liver and abdominal fat by serial imaging. Am J Clin Nutr, 84 (2006), pp. 304-311

51. L. Busetto, G. Segato, M. De Luca, E. Bortolozzi, T. MacCari, A. Magon, et al. Preoperative weight loss by intragastric balloon in super-obese patients treated with laparoscopic gastric banding: a case-control study. Obes Surg, 14 (2004), pp. 671-676

52. Alastrué, P.P. García-Luna, X. Formiguera. Priorización de pacientes en cirugía bariátrica: índice de riesgo. Cir Esp, 75 (2004), pp. 225-231

53. G. Van Den Berghe, P. Wouters, F. Weekers, C. Verwaest, Bruyninckx, M. Schetz, et al. Intensive insulin therapy in critically ill patients. N Engl J Med, 345 (2001), pp. 1359-1367

54. L.I. Kuzmac. Gastric banding. M. Deitel (Ed.), Surgery for morbidly obese patient, Lea \& Febiger, Filadelfia (1989), pp. 225-259

55. M. Belachew, M.J. Legrand, T. Defechereux, M.P. Burtheret, N. Jaquet. Laparoscopic adjustable silicone gastric banding in the treatment of morbid obesity: a preliminary report. Surg Endosc, 8 (1994), pp. 1354-1356

56. F. Favretti, P.E. O’Brien, J.B. Dixon. Patient management after lap-band placement. Am J Surg, 184 (2002), pp. 38S-41S

57. E.E. Mason. Vertical banded gastroplasty for morbid obesity. Arch Surg, 117 (1982), pp. 701 706

58. Alastrué, M. Rull, X. Formiguera, D. Casas, P. Moreno, X. Mira, et al. Cirugía de la obesidad grave. Endocrinol Nutr, 46 (1999), pp. 22-42

59. Baltasar, C. Serra, N. Pérez, R. Bou, M. Bengochea, L. Ferri. Laparoscopic sleeve gastrectomy: a multi-purpose bariatric operation. Obes Surg, 15 (2005), pp. 1124-1128

60. D. Cottam, F.G. Qureshi, S.G. Maltar, S. Sharma, S. Holover, G. Bonanomi, et al. Laparoscopic sleeve gastrectomy as an initial weight-loss procedure for high-risk patients with morbid obesity. Surg Endosc, 20 (2006), pp. 859-863

61. R.T. Jung, A. Cuschieri. Obese patients. A. Cuschieri, R.J.C. Steele, A.R. Moosa (Eds.), Essential Surgical Practice-Volume I (4th edition), Butterworth Heinemann, Oxford (2000), p. 5326

62. H.J. Sugerman, J.V. Starkey, R. Birkenhauer. A randomized prospective trial of gastric bypass versus vertical banded gastroplasty for morbid obesity and their effects on sweets versus nonsweets eaters. Ann Surg, 205 (1987), pp. 613-624

63. H.J. Sugerman, J.M. Kellum, K.M. Engle, L. Wolfe, J.V. Starkey, R. Birkenhauer, et al. Gastric bypass for treating severe obesity. Am J Clin Nutr, 55 (Suppl 2) (1992), pp. 560S-566S

64. M.A. Fobi. Vertical banded gastroplasty vs gastric bypass: 10 Years follow-up. Obes Surg, 3 (1993), pp. 161-164

65. R.E. Brolin, L.E. Robertson, H.A. Kenler, R.P. Cody. Weight loss and dietary intake after vertical banded gastroplasty and Roux-en Y gastric bypass. Ann Surg, 220 (1994), pp. 782-787

66. E.E. Mason, S. Tang, K.E. Renquist, D.T. Barnes, J.J. Cullen, C. Doherty, et al. A decade of change in obesity surgery. National Bariatric Surgery Registry (NBSR) Contributors. Obes Surg, 7 (1997), pp. 189-197

67. L.D. MacLean, B.M. Rhode, J. Sampalis, R.A. Forse. Results of the surgical treatment of obesity. Am J Surg, 165 (1993), pp. 155-160

68. L.D. MacLean, B.M. Rhode, C.W. Nohr. Late outcome of isolated gastric bypass. Ann Surg, 231 (2000), pp. $524-528$

69. W.K. Nelson, J. Fatima, S.G. Houghton, G.B. Thompson, M.L. Kendrick, J.L. Mai, et al. The malabsorptive very, very long limb Roux-en-Y gastric bypass for super obesity: results in 257 patients. Surgery, 140 (2006), pp. 517-522

70. R.E. Brolin, H.A. Kenler, J.H. Gorman, R.P. Cody. Long-limb gastric bypass in the superobese: a prospective, randomized study. Ann Surg, 215 (1992), pp. 387-395

71. P.S. Choban, L. Flancbaum. The effect of Roux limb lengths on outcome after Roux-en-Y gastric bypass: a prospective, randomized clinical trial. Obes Surg, 12 (2002), pp. 540-545 
72. W.B. Inabnet, T. Quinn, M. Gagner, M. Urban, A. Pomp. Laparoscopic Roux-en-Y gastric bypass in patients with $\mathrm{BMI}<50$ : a prospective, randomized trial comparing short and long limb lengths. Obes Surg, 15 (2005), pp. 51-57

73. N. Scopinaro, G.F. Adami, G.M. Marinari, E. Gianetta, E. Traverso, D. Friedman, et al. Biliopancreatic diversion. World J Surg, 22 (1998), pp. 936-946

74. P. Marceau, F.S. Hould, S. Simard, S. Lebel, R.A. Bourque, M. Potvin, et al. Biliopancreatic diversion with duodenal switch. World J Surg, 22 (1998), pp. 947-954

75. Baltasar, R. Bou, M. Bengochea, F. Arlandis, C. Escrivá, J. Miró, et al. Duodenal switch: an effective therapy for morbid obesity - intermediate results. Obes Surg, 11 (2001), pp. 54-58

76. Sánchez-Cabezudo Diaz-Guerra, A. Larrad Jiménez. Analysis of weight loss with the biliopancreatic diversion of Larrad: absolute failures or relative successes?. Obes Surg, 12 (2002), pp. 249-252

77. A.C. Wittgrove, G.W. Clark. Laparoscopic gastric bypass, Roux-en-Y -500 patients: technique and results, with 3-60 month follow-up. Obes Surg, 10 (2000), pp. 233-239

78. N.T. Nguyen, C. Goldman, J. Rosenquist, A. Arango, C.J. Cole, S.J. Lee, et al. Laparoscopic versus open gastric bypass: a randomized study of outcomes, quality of life and costs. Ann Surg, 234 (2001), pp. 279-291

79. Westling, S. Gustavsson. Laparoscopic vs. open Roux.en-Y gastric bypass: a prospective randomized trial. Obes Surg, 11 (2001), pp. 284-292

80. J.A. Lujan, M.D. Frutos, Q. Hernandez, R. Lirón, J.R. Cuenca, G. Valero, et al. Laparoscopic versus open gastric bypass in the treatment of morbid obesity: a randomized prospective study. Ann Surg, 239 (2004), pp. 433-437

81. H. Buchwald, J.N. Buchwald. Evolution of operative procedures for the management of morbid obesity 1950-2000. Obes Surg, 12 (2002), pp. 705-717

82. J.M.V. Pons Rafols, M. Espallargues, C. Tebe. Obesidad y cirugia bariatrica: de último recurso a terapia de primera elección. Med Clin (Barc), 126 (2006), pp. 19-24

83. M.J. Monteforte, C.M. Turkelson. Bariatric surgery for morbid obesity. Obes Surg, 10 (2000), pp. 391-401

84. P.R. Schauer, S. Ikramuddin, W. Gourash, R. Ramanathan, J. Luketich. Outcomes after laparoscopic Roux-en Y gastric bypass for morbid obesity. Ann Surg, 232 (2000), pp. 515-529

85. Baltasar, R. Bou, J. Miró, M. Bengochea, C. Serra, N. Pérez. Laparoscopic biliopancreatic diversion with duodenal switch: technique and initial experience. Obes Surg, 12 (2002), pp. 245-248

86. K. Nilsell, A. Tome, S. Sjosted, J. Apelman, N. Pettersson. Prospective randomised comparison of adjustable gastric banding and vertical banded gastroplasty for morbid obesity. Eur J Surg, 167 (2001), pp. 504-509

87. M. Morino, M. Toppino, G. Bonnet, G. Del Genio. Laparoscopic adjustable silicone gastric banding versus vertical banded gastroplasty in morbidly obese patients: a prospective randomized controlled clinical trial. Ann Surg, 238 (2003), pp. 835-841

88. Agencia de evaluación de tecnologías sanitarias de Galicia (Avalia-t). Subdirección xeral de planificación sanitaria e aseguramento. Secretaría xeral do SERGAS. Evaluación de las técnicas de cirugía bariátrica en el tratamiento de la obesidad mórbida. Santiago de Compostela: Avaliat. Octubre 2001.

89. P.E. O'Brien, T. McPhail, J.B. Dixon. Systematic review of the medium and long term weight loss following bariatric surgery. Obes Res, 13 (2005), p. A194

90. G.S.M. Cowan. Long versus short limb Roux-en-Y procedures. Early results in a prospective randomized study of metabolic, nutritional and anthropometric outcomes. Obes Surg, 6 (1996), p. 25

91. Díez del Val, C. Martínez Blázquez. Cirugía de la obesidad mórbida: medicina basada en la evidencia. Cir Esp, 74 (2003), pp. 185-192

92. D.R. Flum, E.P. Dellinger. Impact of gastric bypass operation on survival: a population-based analysis. J Am Coll Surg, 199 (2004), pp. 543-551

93. N.V. Christou, J.S. Sampalis, M. Liberman, D. Look, S. Auger, A.P. McLean, et al. Surgery decreases long-term mortality, morbidity and health care use in morbidly obese parients. Ann Surg, 240 (2004), pp. 416-423

94. W.J. Pories, M.S. Swanson, K. MacDonald, S.B. Long, P.G. Morris, B.M. Brown, et al. Who would have thought it? An operation proves to be the most effective therapy for adult-onset diabetes mellitus. Ann Surg, 222 (1995), pp. 339-352

95. P.R. Schauer, B. Burguera, S. Ikramuddin, D. Cottam, W. Gourash, G. Hamac, et al. Effect of laparoscopic Roux-en Y gastric bypass on type 2 diabetes mellitus. Ann Surg, 238 (2003), pp. 467-484 
96. H.J. Sugerman, K.G. Wolfe, D.A. Sica, J.N. Clore. Diabetes and hypertension in severe obesity and effects of gastric bypass-induced weight loss. Ann Surg, 237 (2003), pp. 751-756

97. W.J. Pories. Diabetes: the evolution of a new paradigm. Ann Surg, 239 (2004), pp. 12-13

98. K. MacDonald, S. Long, M. Swanson, B. Brown, P. Morris, L. Dohm, et al. The gastric bypass operation reduces the progression and mortality of non-insulin-dependent diabetes mellitus. J Gastrointest Surg, 1 (1997), pp. 213-220

99. F. Rubino, M. Gagner, P. Gentileschi, S. Kini, S. Fukuyama, J. Feng, et al. The early effect of the Roux-en-Y gastric bypass on hormones involved in body weight regulation and glucose metabolism. Ann Surg, 240 (2004), pp. 236-242

100. J.L. Carson, M.E. Ruddy, A.E. Duff, N.J. Holmes, R.P. Cody, R.E. Brolin. The effect of gastric bypass surgery on hypertension in morbidly obese patients. Arch Intern Med, 154 (1994), pp. 193-200

101. G.S. Cowan Jr, C.K. Buffington. Significant changes in blood pressure, glucose and lipids with gastric bypass surgery. World J Surg, 22 (1998), pp. 987-992

102. J.J. Gleysteen. Results of surgery: long-term effects on hyperlipidemia. Am J Clin Nutr, 55 (1992), pp. 591S-593S

103. R.E. Brolin, R.J. Bradley, A.C. Wilson, R.P. Cody. Lipid risk profile and weight stability after gastric restrictive operations. J Gastrointest Surg, 4 (2000), pp. 464-469

104. L. Busseto, C. Pisent, D. Rinaldi, P.L. Longhin, G. Segato, F. De Marchi, et al. Variation in lipid levels in morbidly obese patients operated with Lap-Band adjustable gastric banding system: effects of different levels of weight loss. Obes Surg, 10 (2000), pp. 569-577

105. G. Skroubis, S. Anesidis, I. Kehagias, N. Mead, K. Vagenas, F. Kalfarentzos. Roux-en-Y gastric bypass versus a variant of biliopancreatic diversion in a non-superobese population: prospective comparison of the efficacy and the incidence of metabolic deficiencies. Obes Surg, 16 (2006), pp. 488-495

106. P. Poirier, J. Martin, P. Marceau, S. Biron, S. Marceau. Impact of bariatric surgery on cardiac structure, function and clinical manifestations in morbid obesity. Expert Rev Cardiovasc Ther, 2 (2004), pp. 193-201

107. S. Kyzer, I. Charuzi. Obstructive sleep apnea in the obese. World J Surg, 22 (1998), pp. 998 1001

108. H.J. Sugerman, R.P. Fairman, R.K. Sood, K. Engle, L. Wolfe, J.M. Kellum. Long-term effects of gastric surgery for treating respiratory insufficiency of obesity. Am J Clin Nutr, 55 (1992), pp. 597S-601S

109. J.B. Dixon, L.M. Schachter, P.E. O’Brien. Sleep disturbance and obesity: changes following surgically induced weight loss. Arch Intern Med, 161 (2001), pp. 102-106

110. M. Peltonen, A.K. Lindroos, J.S. Torgerson. Muskuloskeletal pain in the obese: a comparison with the general population and long-term changes after conventional and surgical obesity treatment. Pain, 104 (2003), pp. 549-557

111. J. Parvizi, R.T. Trousadale, M.G. Sarr. Total joint arthroplasty in patients surgically treated for morbid obesity. J Arthroplasty, 15 (2000), pp. 1003-1008

112. A.E. Chapman, G. Kiroff, P. Game, B. Foster, P. O’Brien, J. Ham, et al .Laparoscopic adjustable gastric banding in the treatment of obesity: a systematic literature review. Surgery, 135 (2004), pp. 326-351

113. R.D. Bloomberg, A. Fleishman, J.E. Nalle, D.M. Herron, S. Kini. Nutritional deficiencies following bariatric surgery: what have we learned?. Obes Surg, 15 (2005), pp. 145-154

114. J.I. Alvarez-Leite. Nutrient deficiencies secondary to bariatric surgery. Curr Opin Clin Nutr Metab Care, 7 (2004), pp. 569-575

115. G. Skroubis, G. Sakellaropoulos, K. Pouggourask, N. Mead, G. Nikiforidis, F. Kalfarentzos. Comparison of nutritional deficiencies after Rouxen-Y gastric bypass and after biliopancreatic diversion with Roux-en-Y gastric bypass. Obes Surg, 12 (2002), pp. 551-558

116. Vázquez, E. Morejón, C. Muñoz, Y. López, J. Balsa, M.A. Koning, et al. Efecto nutricional de la cirugía bariátrica con la operación de Scopinaro. Análisis de 40 casos. Nutr Hosp, 18 (2003), pp. 189-193

117. J. Ocón Bretón, S. Pérez Naranjo, S. Gimeno Laborda, P. Benito Ruesca, R. García Hernández. Efectividad y complicaciones de la cirugía bariátrica en el tratamiento de la obesidad mórbida. Nutr Hosp, 20 (2005), pp. 409-414

118. Manterola, V. Pineda, M. Vial, H. Losada, S. Muñoz. Surgery for morbid obesity: selection of operation based on evidence from literature review. Obes Surg, 15 (2005), pp. 106-113

119. Naslund, P. Gryback, P.M. Hellstrom, H. Jacobsson, J.J. Holst, E. Theodorsson, et al. Gastrointestinal hormones and gastric emptying 20 years after jejunoileal bypass for massive obesity. Int J Obes Relat Metab Disord, 21 (1997), pp. 387-392 
120. M. Álvarez Bartolomé, M. Borque, J. Martínez-Sarmiento, E. Aparicio, C. Hernández, L. Cabrerizo, et al. Peptide YY secretion in morbidly obese patients before and after vertical banded gastroplasty. Obes Surg, 12 (2002), pp. 324-327

121. D.E. Cummings, O.S. Weigle, R.S. Frayo, P.A. Breen, M.K. Ma, E.P. Dellinger, et al .Plasma ghrelin levels after diet-induced weight loss or gastric bypass surgery. N Engl J Med, 23 (2002), pp. $1623-1630$

122. G. Fruhbeck, A. Díez-Caballero, M.J. Gil. Fundus functionality and ghrelin concentrations after bariatric surgery. N Engl J Med, 15 (2004), pp. 308-309

123. R. Morínigo, V. Moizé, M. Musri, A.M. Lacy, S. Navarro, J.L. Marín, et al. Glucagon-like peptide-1, peptide YY, hunger and satiety after gastric bypass surgery in morbidly obese subjects. J Clin Endocrinol Metab, 91 (2006), pp. 1735-1740

124. R.E. Brolin, H.A. Kenler, R.C. Gorman, R.P. Cody. The dilemma of outcome assessment after operations for morbid obesity. Surgery, 105 (1989), pp. 337-346

125. G.H. Ballantyne. Measuring outcomes following bariatric surgery: weight loss parameters, improvement in comorbid conditions, change in quality of life and patient satisfaction. Obes Surg, 13 (2003), pp. 954-964

126. H.E. Oria, M.K. Moorehead. Bariatric analysis and reporting outcome system (BAROS). Obes Surg, 8 (1998), pp. 487-499

127. M.K. Moorehead, E. Ardelt-Gattinger, H. Lechner, H.E. Oria. The validation of the MooreheadArdelt quality of life questionnaire. Obes Surg, 13 (2003), pp. 684-692

128. J.E. Ware, C.D. Sherbourne. The MOS 36-item short-form health survey (SF-36): conceptual framework and item selection. Med Care, 30 (1992), pp. 473-483

129. S.P. McKenna, S.M. Hunt, A. Tennant. The development of a patient-completed index of distress from the Nottingham Health Profile: a new measure for use in cost-utility studies. Br J Med Econ, 6 (1993), pp. 13-24

130. Eypasch, J.J. Williams, S. Wood-Dauphinee, B.M. Ure, C. Schnulling, E. Neugebauer, et al. Gastrointestinal Quality of Life index: development, validation and application of a new instrument. Br J Surg, 82 (1995), pp. 216-222

131. Poves Prim, G.J. Macías, M. Cabrera Fraga, L. Situ, C. Ballesta. Calidad de vida en la obesidad mórbida. Rev Esp Enferm Dig, 97 (2005), pp. 187-195

132. M. Bohn, M. Way, A. Jamieson. The effect of practical dietary counseling on food variety and regurgitation frequency after gastroplasty for obesity. Obes Surg, 3 (1993), pp. 23-28

133. K. Fujioka. Follow-up of nutritional and metabolic problems after bariatric surgery. Diabetes Care, 28 (2005), pp. 481-484

134. V. Moize, A. Geliebter, M.E. Gluck, E. Yahav, M. Lorence, T. Colarusso, et al. Obese patients have inadequate protein intake related to protein intolerance up to 1 year following Roux-en-Y gastric bypass. Obes Surg, 13 (2003), pp. 23-28

135. M.A. Rubio, C. Martínez, O. Vidal, A. Larrad, J. Salas-Salvado, J. Pujol, et al. Documento de consenso sobre cirugía bariátrica. SEEDO-SECO. Rev Esp Obes, 4 (2004), pp. 223-249

136. R. Kushner. Managing the obese patient after bariatric surgery: a case report of severe malnutrition and review of the literature. J Parenter Enteral Nutr, 24 (2000), pp. 126-132

137. C.S. Huang, R.A. Forse, B.C. Jacobson, F.A. Farraye. Endoscopic findings and their clinical correlations in patients with symptoms after bypass surgery. Gastrointest Endosc, 58 (2003), pp. 859-866

138. J. Ahmad, J. Martin, S. Ikramuddin, P. Schauer, A. Slivka. Endoscopic balloon dilatation of the gastroenteric anastomotic stricture after laparoscopic gastric bypass. Endoscopy, S35 (2003), pp. 725-728

139. L.J. Wudel Jr, J.K. Wright, J.P. Debelak, T.M. Allos, Y. Shyr, C. Chapman. Prevention of gallstone formation in morbidly obese patients undergoing rapid weight loss: results of a randomized controlled pilot study. J Surg Res, 102 (2002), pp. 50-56

140. H.J. Sugerman, W.H. Brewer, M.L. Shiffman, R.E. Brolin, M.A. Fobi, J.H. Linner. A multicenter, placebo-controlled, randomized, double-blind, prospective trial of prophylactic ursodiol for the prevention of gallstone formation following gastric-bypass-induced rapid weight loss. Am J Surg, 169 (1995), pp. 91-96

141. Avinoah, A. Ovnat, I. Charuzi. Nutritional status seven years after Roux-en-Y gastric bypass surgery. Surgery, 111 (1992), pp. 137-142

142. B.M. Rhode, C. Shustik, N.V. Christou, L.D. MacLean. Iron absorption and therapy after gastric bypass. Obes Surg, 9 (1999), pp. 17-21

143. D. Provenzale, R.B. Reinhold, B. Golner, V. Irwin, G.E. Dallal, N. Papathanasopoulos, et al. Evidence for disminished B12 absorption after gastric bypass: oral supplementation does not prevent low plasma B12 levels in bypass patients. J Am Coll Nutr, 11 (1992), pp. 29-35 
144. B.M. Rhode, P. Arseneau, B.A. Cooper, M. Katz, B.M. Gilfix, L.D. MacLean. Vitamin B12 deficiency after gastric surgery for obesity. Am J Clin Nutr, 63 (1996), pp. 103-109

145. L. Newbury, K. Dolan, M. Hatzifotis, N. Low, G. Fielding. Calcium vitamin D depletion and elevated parathyroid hormone following biliopancreatic diversion. Obes Surg, 13 (2003), pp. 893-895

146. N. Hamoui, K. Kim, G. Anthony, P.F. Crookes. The significance of elevated evels of parathyroid hormone in patients with morbid obesity before and after bariatric surgery. Arch Surg, 138 (2003), pp. 891-897

147. R.E. Brolin, L.B. LaMarca, H.A. Kenler, R.P. Cody. Malabsorptive gastric ypass in patients with superobesity. J Gastrointest Surg, 6 (2002), pp. 195-203

148. P.S. Coates, J.D. Fernstrom, M.H. Fernstrom, P.R. Schauer, S.L. Greenspan. Gastric bypass surgery for morbid obesity leads to an increase in bone turnover and a decrease in bone mass. $\mathrm{J}$ Clin Endocrinol Metab, 89 (2004), pp. 1061-1065

149. M.L. Collazo-Clavell, A. Jiménez, S.F. Hodgson, M.G. Sarr. Osteomalacia after Roux-en-Y gastric bypass. Endocr Pract, 10 (2004), pp. 195-198

150. M.A. Von Mach, R. Stoeckli, S. Bilz, M. Kraenzlin, I. Langer, U. Keller. Changes in bone mineral content after surgical treatment of morbid obesity. Metabolism, 53 (2004), pp. 918-921

151. L.R. Goode, R.E. Brolin, H.A. Chowdhury, S.A. Shapses. Bone and gastric bypass surgery: effects of dietary calcium and vitamin D. Obes Res, 12 (2004), pp. 40-47

152. N. Hamoui, G. Anthone, P.F. Crookes. Calcium metabolism in the morbidly obese. Obes Surg, 14 (2004), pp. 9-12

153. A.M. Carlin, D.S. Rao, A.M. Melemani, J.A. Genaw, N. Parikh, S. Levy, et al. Prevalence of vitamin D depletion among morbidly obese patients seeking gastric bypass surgery. Surg Obes Relat Dis, 2 (2006), pp. 98-104

154. G.H. Slater, C.J. Ren, N. Siegel, T. Williams, D. Barr, B. Wolfe, et al. Serum fat-soluble vitamin deficiency and abnormal calcium metabolism after malabsorptive bariatric surgery. $\mathrm{J}$ Gastrointest Surg, 8 (2004), pp. 48-55

155. S. Marceau, S. Biron, M. Lagace, F.S. Hould, M. Potvin, R.A. Bourque, et al. Biliopancreatic diversion, with distal gastrectomy, $250 \mathrm{~cm}$ and $50 \mathrm{~cm}$ limbs: long-term results. Obes Surg, 5 (1995), pp. 302-307

156. R.A. Rabkin, J.M. Rabkin, B. Metcalf, M. Lazo, M. Rossi, L.B. Lehman-Becker. Nutritional markers following duodenal switch for morbid obesity. Obes Surg, 14 (2004), pp. 84-90

157. J.M. Rhodes, P. Middleton, D.P. Jewell. The lactulose hydrogen breath test as a diagnostic test for small-bowel bacterial overgrowth. Scand J Gastroenterol, 14 (1979), pp. 333-336

158. M. Deitel, E. Stone, H.A. Kassam, E.J. Wilk, D.J. Sutherland. Gynecologic-obstetric changes after loss of massive excess weight following bariatric surgery. J Am Coll Nutr, 7 (1988), pp. 147-153

159. Escobar-Morreale, J.I. Botella-Carretero, F. Alvarez-Blasco, J. Sancho, J.L. San Millán. The polycystic ovary syndrome associated with morbid obesity may resolve after weight loss induced by bariatric surgery. J Clin Endocrinol Metab, 90 (2005), pp. 6364-6369

160. E. Sheiner, J.S. Abramowicz, I. Levy, M. Katz, M. Mazor. Pregnancy outcome of patients with gestational diabetes mellitus following bariatric surgery. Am J Obstet Gynecol, 194 (2006), pp. 431-435

161. L.F. Martin, K.M. Finnan, T. Nolan. Pregnancy after adjustable gastric banding. Obstet Gynecol, 95 (2000), pp. 927-930

162. K.J. Printen, D. Scott. Pregnancy following gastric bypass for the treatment of morbid obesity. Am Surg, 48 (1982), pp. 363-365

163. A.C. Wittgrove, L. Jester, P. Wittgrove, G.W. Clark. Pregnancy following gastric bypass for morbid obesity. Obes Surg, 8 (1998), pp. 461-464

164. D. Friedman, S. Cuneo, M. Valenzano, G.M. Marinari, G.F. Adami, E. Gianetta, et al. Pregnancies in an 18-year follow-up after biliopancreatic diversion. Obes Surg, 5 (1995), pp. 308-313

165. P. Marceau, S. Biron, F.S. Hould, S. Lebel, Marceau, J.G. Kral. Outcome of pregnancies alter biliopancreatic diversion. Obes Surg, 3 (2004), pp. 318-324

166. N. Kakarla, N. Dailey, T. Murino, S.A. Shikora, D. Chelmow. Pregnancy after bypass surgery and internal hernia formation. Obst Gynecol, 105 (2005), pp. 1195-1198

167. J.B. Dixon, M.E. Dixon, P.E. O'Brien. Pregnancy after Lap-Band surgery: management of the band to achieve health weight outcomes. Obes Surg, 11 (2001), pp. 59-65

168. C.S. Rand, A.M. Macgregor. Medical care and pregnancy outcome after gastric bypass surgery for obesity. South Med J, 82 (1989), pp. 1319-1320 